OPEN ACCESS

Edited by:

Enrique Fernandez-Caldas,

Inmunotek SL, Spain

Reviewed by:

Nathalie Acevedo,

University of Cartagena, Colombia

Claudia Alessandri,

Centri Associati Allergologia

Molecolare, Italy

*Correspondence:

Philip J. Cooper

pcooper@sgul.ac.uk

†These authors have contributed equally to this work

Specialty section:

This article was submitted to

Allergens,

a section of the journa

Frontiers in Allergy

Received: 28 March 2021

Accepted: 12 July 2021

Published: 05 August 2021

Citation:

Cooper PJ, Chis Ster I, Chico ME, Vaca M, Barreto ML and Strachan DP

(2021) Patterns of Allergic Sensitization and Factors Associated With Emergence of Sensitization in the Rural Tropics Early in the Life Course: Findings of an Ecuadorian Birth Cohort. Front. Allergy 2:687073. doi: 10.3389/falgy.2021.687073

\section{Patterns of Allergic Sensitization and Factors Associated With Emergence of Sensitization in the Rural Tropics Early in the Life Course: Findings of an Ecuadorian Birth Cohort}

\author{
Philip J. Cooper ${ }^{1,2,3 *}$, Irina Chis Ster ${ }^{1}$, Martha E. Chico ${ }^{3}$, Maritza Vaca ${ }^{3}$, \\ Mauricio L. Barreto ${ }^{4 \dagger}$ and David P. Strachan ${ }^{5+}$ \\ 'Institute of Infection and Immunity, St George's University of London, London, United Kingdom, ${ }^{2}$ Escuela de Medicina, \\ Universidad Internacional del Ecuador, Quito, Ecuador, ${ }^{3}$ Fundacion Ecuatoriana Para Investigacion en Salud, Quito, Ecuador, \\ ${ }^{4}$ Center for Data and Knowledge Integration for Health (CIDACS)-Fundação Oswaldo Cruz, Salvador, Brazil, ${ }^{5}$ Population \\ Health Research Institute, St George's University of London, London, United Kingdom
}

Introduction: There are limited data on emergence of allergic sensitization (or atopy) during childhood in tropical regions.

Methods: We followed a birth cohort of 2,404 newborns to 8 years in tropical Ecuador and collected: risk factor data by maternal questionnaires periodically from birth; atopy was measured by skin prick test reactivity (SPT) to aeroallergens in parents, and aeroallergens and food allergens in children at 2, 3, 5, and 8 years; and stool samples for soil-transmitted helminths (STH) from children periodically to 8 years and from parents and household members at the time of recruitment of cohort children. Data on risk factors were measured either at birth or repeatedly (time-varying) from birth to 8 years. Longitudinal repeated-measures analyses were done using generalized estimating equations to estimate the age-dependent risk of positive SPT (SPT+) to any allergen or mite during early childhood.

Results: SPT+ to any allergen was present in 29.0\% of fathers and $24.8 \%$ of mothers, and in cohort children increased with age, initially to mite but later to cockroach, reaching $14.8 \%$ to any allergen (10.7\% mite and 5.3\% cockroach) at 8 years. Maternal SPT+, particularly presence of polysensitization (OR 2.04, 95\% Cl 1.49-2.77) significantly increased the risk of SPT+ during childhood, while household overcrowding at birth decreased the risk $(\mathrm{OR} 0.84,95 \% \mathrm{Cl}$ 0.72-0.98). For mite sensitization, maternal polysensitization increased (OR 2.14, 95\% Cl 1.40-3.27) but rural residence (OR 0.69, 95\% Cl 0.50-0.94) and birth order (3rd-4th vs. 1st-2nd: OR 0.71, 95\% Cl 0.52-0.98) decreased the risk. Time-varying exposures to agricultural activities (OR 0.77, 95\% Cl 0.60-0.98) and STH parasites (OR 0.70, 95\% Cl 0.64-0.91) during childhood decreased while anthelmintics increased the childhood risk (OR 1.47, 95\% Cl 1.05-2.05) of mite sensitization. 
Conclusion: Our data show the emergence of allergic sensitization, primarily to mite and cockroach allergens, during childhood in tropical Ecuador. A role for both antenatal and post-natal factors acting as potential determinants of SPT+ emergence was observed.

Keywords: allergic sensitization, atopy, cohort, childhood, tropics, risk factors

\section{INTRODUCTION}

Allergen sensitization or atopy represents a predisposition of humans to generate $\operatorname{IgE}$ responses to biochemically heterogeneous molecules present in the environment. These molecules or allergens are derived from sources including arthropods, pollens, molds, and foods. Sensitization rates vary between populations according to host genetic factors, the allergens to which a population is exposed, and the presence of environmental exposures that modify the expression of atopy (1). Allergen sensitization can be measured in epidemiological studies either by the presence of IgE-mediated inflammation to allergen extracts in vivo by skin prick testing or by detection of specific IgE in blood samples. Atopy is an important risk factor for the development of common inflammatory diseases such as asthma, eczema, rhinitis, and food allergy $(1,2)$.

There are numerous epidemiological studies from both highincome and low and middle-income countries on rates of allergen sensitization in general population samples and in children and adults with and without evidence of allergic diseases (2-4). These studies show that the prevalence and specificities of allergen sensitization varies considerably across populations $(5,6)$. Although studies from tropical settings are less common, most have shown in both population-based and patient-based studies that the primary allergen sensitizers are arthropod species including dust mites and cockroaches that thrive in these warm and humid environments (6). There are few published longitudinal studies of the emergence of allergic sensitization early in the life course from tropical regions $(7,8)$ that have studied the role of antenatal and post-natal host and environmental factors as risk factors for allergic sensitization.

We have shown previously in a birth cohort, from a tropical rural district of coastal Ecuador, followed to 8 years of age, that childhood and or maternal STH parasites protected against the development of mite sensitization at 3 years (9), to perennial allergens at 5 years of age (10), and to any allergen when measured at 8 years of age (11). In the present analysis, we describe the development and patterns of allergic sensitization measured by allergen SPT + to school age and explore the potential role of a range of relevant ante-natal and post-natal individual and environmental risk factors, with a particular focus on the role of exposures associated with poor hygiene, in determining the emergence early in the life course of SPT + in this tropical setting.

\footnotetext{
Abbreviations: AIC, Akaike's information criterion; CI, confidence interval; GEE, generalized estimation equations; LMIC, low and middle-income country; OR, odds ratio; SPT, allergen skin prick testing; SPT + , allergen skin prick test positivity; STH, soil-transmitted helminths; Th2, T helper cell type 2 .
}

\section{MATERIALS AND METHODS}

\section{Study Area and Population}

Detailed methodology of the study objectives, design, followup, and sample and data collection for the ECUAVIDA birth cohort study are provided elsewhere (12). Briefly, newborns whose families lived in the rural district of Quininde, Esmeraldas Province, were recruited around the time of birth at the Hospital Padre Alberto Buffoni (HPAB) in the town of Quininde between November 2005 and December 2009. The District is largely agricultural where the main economic activities relate to the cultivation of African palm oil and cocoa. The climate is humid tropical with temperatures generally ranging $23-32^{\circ} \mathrm{C}$ with yearly rainfall of around 2,000-3,000 $\mathrm{mm}$. Inclusion criteria were being a healthy baby, collection of a maternal stool sample, and planned family residence in the district for at least 3 years.

\section{Sample and Data Collection}

Children were followed-up from birth to 8 years of age with data and samples including stools collected at baseline during the initial home visit within 2 weeks of birth and at 7 and 13 months, 2, 3, 5, and 8 years of age. Stool samples were collected from mothers during the third trimester of pregnancy and from household members during the initial home visit around the time of birth of the child. Follow-ups were done either by scheduled visits to a dedicated clinic at HPAB or by home visits. At the initial home visit, a questionnaire was administered to the child's mother by a trained member of the study team to collect data on risk factors, potential confounders, and allergic diseases. Maternal questionnaires were repeated at the time points listed above. Presence of allergic disease symptoms at 8 years of age were defined as described $(11,13)$.

\section{Stool Examinations}

Stool samples were examined using four microscopic techniques to detect soil-transmitted helminth eggs and larvae including direct saline wet mounts, formol-ether concentration, modified Kato-Katz, and carbon coproculture (14). All stool samples were examined using all 4 microscopic methods where stool quantity was adequate. A positive sample was defined by the presence of at least one egg or larva from any of the above detection methods. Parasite burdens with A. lumbricoides and T. trichiura were quantified as eggs per gram (epg) of stool using the results of the modified Kato-Katz method and categorized into light, moderate, and heavy intensities using WHO criteria (14) as follows: A. lumbricoides (light-1-4,999; moderate-5,00049,999; and heavy— $\geq 50,000 \mathrm{epg}$ ) and T. trichiura (light-1-999; moderate $-1000-9,999$; and heavy $-\geq 10,000$ epg). 


\section{Allergen Skin Prick Test Reactivity}

Allergic sensitization was measured by SPTs and done on fathers and mothers of cohort children and on cohort children at 2, 3, 5, and 8 years. SPT on parents used the following allergen extracts: house dust mites (Dermatophagoides pteronyssinus/Dermatophagoides farinae mix) (Greer laboratories, Lenoir, North Carolina, USA), American cockroach (Periplaneta americana) (Greer), cat (Greer), dog (Greer), grass pollen ( 9 southern grass mix containing pollen from Bermuda, Kentucky Blue/June, Johnson, Meadow Fescue, Orchard, Perennial Ryegrass, Redtop, Sweet Vernal, and Timothy grasses) (Greer), fungi [New stock fungi mix containing Acremonium strictum, Alternaria alternata, Aspergillus niger, Aureobasidium pullulans, Bipolaris sorokiniana, Botrytis cinerea, Candida albicans, Chaetomium globosum, Cladosporium sphaerospermum, Epicoccum nigrum, Fusarium moniliforme, Mucor plumbeus, Penicillium chrysogenum (notatum), Phoma betae, Rhizopus stolonifer, and Trichophyton mentagrophytes] (Greer), Alternaria tenuis (Greer), Blomia tropicalis (Leti Pharma, Barcelona, Spain), and Chortoglyphus arcuatus (Leti) with positive histamine $(10 \mathrm{mg} / \mathrm{mL}$ ) (ALK-Abello, Horsholm, Denmark) and negative saline controls (ALK-Abello). SPT on children used the following 9 allergen extracts (all Greer): house dust mites (Dermatophagoides pteronyssinus/Dermatophagoides farinae mix), American cockroach (Periplaneta americana), cat, dog, grass pollen ( 9 southern grass mix), fungi (New stock fungi mix), egg, milk, and peanut, with positive histamine $(10 \mathrm{mg} / \mathrm{mL})$ and negative saline controls (ALK-Abello, Horsholm, Denmark). A positive reaction was defined as a mean wheal diameter (mean of longest and orthogonal diameters) at least $3 \mathrm{~mm}$ greater than the saline control $15 \mathrm{~min}$ after pricking the allergen onto the forearm with lancets (ALK-Abello). Atopy was defined as a positive reaction to any of the allergens tested. Polysensitization was defined as $\geq 2$ positive tests to the same panel of 6 allergens which were tested in both children and parents.

\section{Anthelmintic Treatments}

Individuals with positive stools for STH infections were treated with a single dose of $400 \mathrm{mg}$ albendazole if aged 2 years or greater and with pyrantel pamoate $(11 \mathrm{mg} / \mathrm{kg})$ if aged $<2$ years, according to Ecuadorian Ministry of Public Health recommendations (13). Pregnant women were offered treatment after the delivery of their child. All treatments were provided free by members of the study team.

\section{Statistical Analysis}

The original cohort was designed to study associations between STH infections and allergic outcomes with follow-up to 5 years which was later extended to 8 years (15). SPT + to any allergen and to mite defined two longitudinal binary outcomes. SPT testing was done at 24, 36, 60, and 96 months of age with some time variation but for purposes of analyses, follow-up dates were considered fixed. We use generalized estimation equations (GEEs) to fit population-averaged models $(16,17)$ for effects of age, child, parental, household, and poor hygiene characteristics. The assumption of the correlation structure was that of unstructured (the most general) (16-18). Adjusted associations of longitudinal outcomes with risk factors were assessed using adjusted odds ratios and their 95\% confidence intervals with significance level set to 0.05 . ORs derived from these longitudinal models estimated associations between potential explanatory variables and the age-dependent risk of SPT + . Conceptually, the interpretation is equivalent to a cross-sectional OR. Longitudinal ORs allow stratification of the age-dependent risk of infection by categories of predictors-these are non-linear relationships and an OR $>1$ represents a higher risk of SPT + associated with that category compared to the baseline category across all ages, assuming no interaction with age. Minimally adjusted models (for age and age $^{2}$ ) assessed associations of each factor with risk of SPT + . Multivariable models were built using variables with $P<0.1$ in minimally adjusted models. Among highly correlated variables considered for inclusion in multivariable analyses (Table 1), the variable/s with the smallest associated quasi-likelihood under the independence model criterion (QIC) criterion for GEEs $(19,20)$ on the same data sample were chosen. The QIC criterion is an adaptation of the Akaike's information criterion (AIC) criterion for GEEs for model choice $(18,19)$. The final most parsimonious model derived on a complete data sample was subsequently fit back to the original data on as many observations as possible.

Longitudinal cohorts are subject to attrition at follow-up. We investigated patterns in missing data for SPT + to any allergen and carried out sensitivity analyses by generating new outcomes where 1 indicated a missing observation and 0 otherwise. Sensitivity analyses to missing data are available upon request. The GEE estimation is based on missing completely at random assumption (21). However, random effects based on maximum likelihood estimation were also fit and did not produce very different estimates in terms of magnitude or precision of ORs. This type of estimation, more sensitive to distributional assumptions, was made under missing at random assumption (20). Urban-rural residence was defined by geographic boundaries. All statistical analyses were done using Stata 16 (Statacorp, College Station, Tex).

\section{Ethical Considerations}

Study protocols were approved by ethics committees in Ecuador (Hospital Pedro Vicente Maldonado, Universidad San Francisco de Quito, and Universidad Internacional del Ecuador) and UK (London School of Hygiene and Tropical Medicine). The study is registered as an observational study (ISRCTN41239086). Informed written consent was obtained from the child's mother and minor assent was obtained from the child at 8 years.

\section{RESULTS}

\section{Cohort Participants and Characteristics}

Analyses during the first 8 years of life used data from all 2,404 children with data for SPT at 1 or more of the 4 observation times from 2 years: $97.0 \%$ of children had SPT for at least one observation time and $72.7 \%$ had SPT from all 4 observation times. A total of $1,952(81.2 \%)$ had data on SPT at 8 years. Figure 1 shows numbers sampled for SPT between 2 and 8 years. Characteristics of the 2,404 newborns at the time of birth 
TABLE 1 | Minimally age-adjusted associations between risk of allergen skin prick test positivity (SPT+) to any and to mite allergens during first 8 years of life and child, parental, household, and hygiene factors.

\begin{tabular}{|c|c|c|c|c|c|c|c|c|c|}
\hline Variable & $N(\%)$ & \multicolumn{4}{|c|}{ SPT+ to any allergen } & \multicolumn{4}{|c|}{ SPT+ to mite } \\
\hline \multicolumn{10}{|l|}{ Gender } \\
\hline Male & 1,193 (51.2\%) & 1 & & & & 1 & & & \\
\hline Female & 1,139 (48.8\%) & 0.88 & 0.73 & -1.06 & 0.185 & 0.91 & 0.72 & -1.17 & 0.466 \\
\hline 0-6 months & 232 (10.5\%) & 1 & & & & 1 & & & \\
\hline $7-12$ months & $956(43.3 \%)$ & 0.93 & 0.67 & -1.27 & 0.628 & 0.67 & 0.45 & -0.99 & 0.044 \\
\hline$>12$ months & 1,022 (46.2\%) & 0.91 & 0.66 & -1.24 & 0.541 & 0.74 & 0.51 & -1.10 & 0.126 \\
\hline \multicolumn{10}{|c|}{ MATERNAL FACTORS } \\
\hline \multicolumn{10}{|l|}{ Age (years) } \\
\hline$\leq 20$ & $622(26.7 \%)$ & 1 & & & & 1 & & & \\
\hline Afro-Ecuadorian & 599 (25.7\%) & 1 & & & & 1 & & & \\
\hline Non-Afro-Ecuadorian & $1,733(74.3 \%)$ & 0.97 & 0.79 & -1.20 & 0.774 & 0.84 & 0.64 & -1.10 & 0.2 \\
\hline \multicolumn{10}{|l|}{ Education } \\
\hline Illiterate & $353(15.1 \%)$ & 1 & & & & 1 & & & \\
\hline Primary & $1,370(58.8 \%)$ & 1.17 & 0.88 & -1.54 & 0.287 & 1.31 & 0.88 & -1.93 & 0.183 \\
\hline Secondary & $609(26.1 \%)$ & 1.34 & 0.99 & -1.82 & 0.06 & 1.70 & 1.12 & -2.59 & 0.013 \\
\hline \multicolumn{10}{|l|}{ Allergic symptoms } \\
\hline No & 2,204 (95.1\%) & 1 & & & & 1 & & & \\
\hline Yes & $113(4.9 \%)$ & 1.62 & 1.12 & -2.36 & 0.011 & 1.43 & 0.86 & -2.37 & 0.17 \\
\hline \multicolumn{10}{|l|}{ Allergen SPT+ } \\
\hline \multicolumn{10}{|l|}{ Age (years) } \\
\hline$\leq 20$ & $188(8.1 \%)$ & 1 & & & & 1 & & & \\
\hline $21-29$ & 1,027 (44.0\%) & 0.82 & 0.59 & -1.15 & 0.251 & 1.06 & 0.67 & -1.70 & 0.800 \\
\hline$\geq 30$ & 1,117 (47.9\%) & 0.78 & 0.56 & -1.08 & 0.138 & 0.99 & 0.62 & -1.57 & 0.953 \\
\hline \multicolumn{10}{|l|}{ Ethnicity } \\
\hline Afro-Ecuadorian & $526(23.3 \%)$ & 1 & & & & 1 & & & \\
\hline Non-Afro-Ecuadorian & 1,734 (76.7\%) & 0.89 & 0.72 & -1.10 & 0.279 & 0.81 & 0.61 & -1.07 & 0.135 \\
\hline Education & & & & & & & & & \\
\hline Illiterate & 330 (15.5\%) & 1 & & & & 1 & & & \\
\hline Primary & 1,130 (53.0\%) & 0.96 & 0.73 & -1.27 & 0.795 & 1.15 & 0.78 & -1.68 & 0.486 \\
\hline Secondary & $672(31.5 \%)$ & 1.00 & 0.75 & -1.35 & 0.979 & 1.19 & 0.76 & -1.73 & 0.508 \\
\hline Allergic symptoms & & & & & & & & & \\
\hline No & 2,074 (96.4\%) & 1 & & & & 1 & & & \\
\hline Yes & 77 (3.6\%) & 0.77 & 0.44 & -1.35 & 0.363 & 0.79 & 0.38 & -1.66 & 0.533 \\
\hline Allergen SPT+ & & & & & & & & & \\
\hline No & $843(70.8 \%)$ & 1 & & & & 1 & & & \\
\hline Yes & 348 (29.2\%) & 1.27 & 0.97 & -1.66 & 0.083 & 1.28 & 0.90 & -1.84 & 0.173 \\
\hline
\end{tabular}


TABLE 1 | Continued

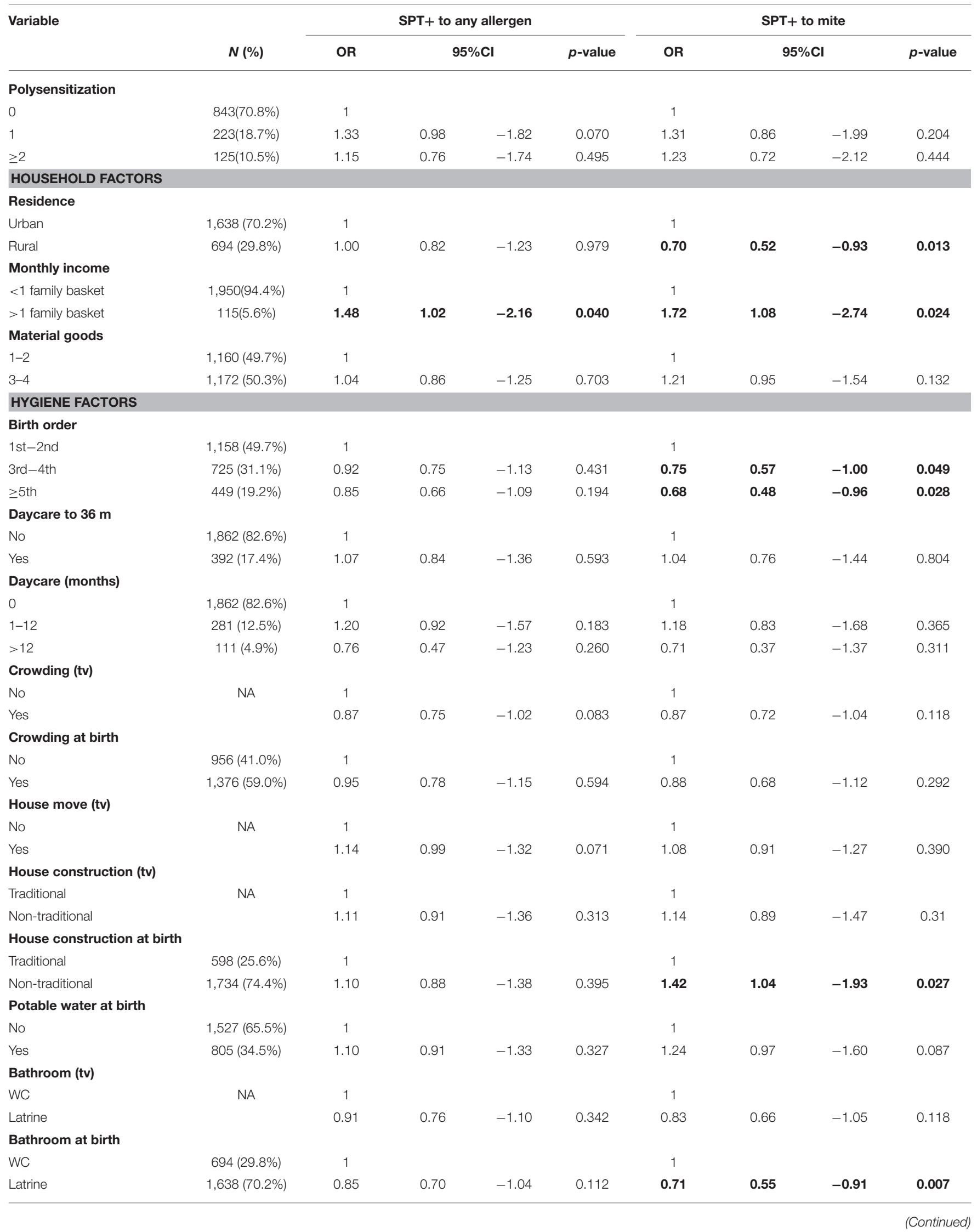


TABLE 1 | Continued

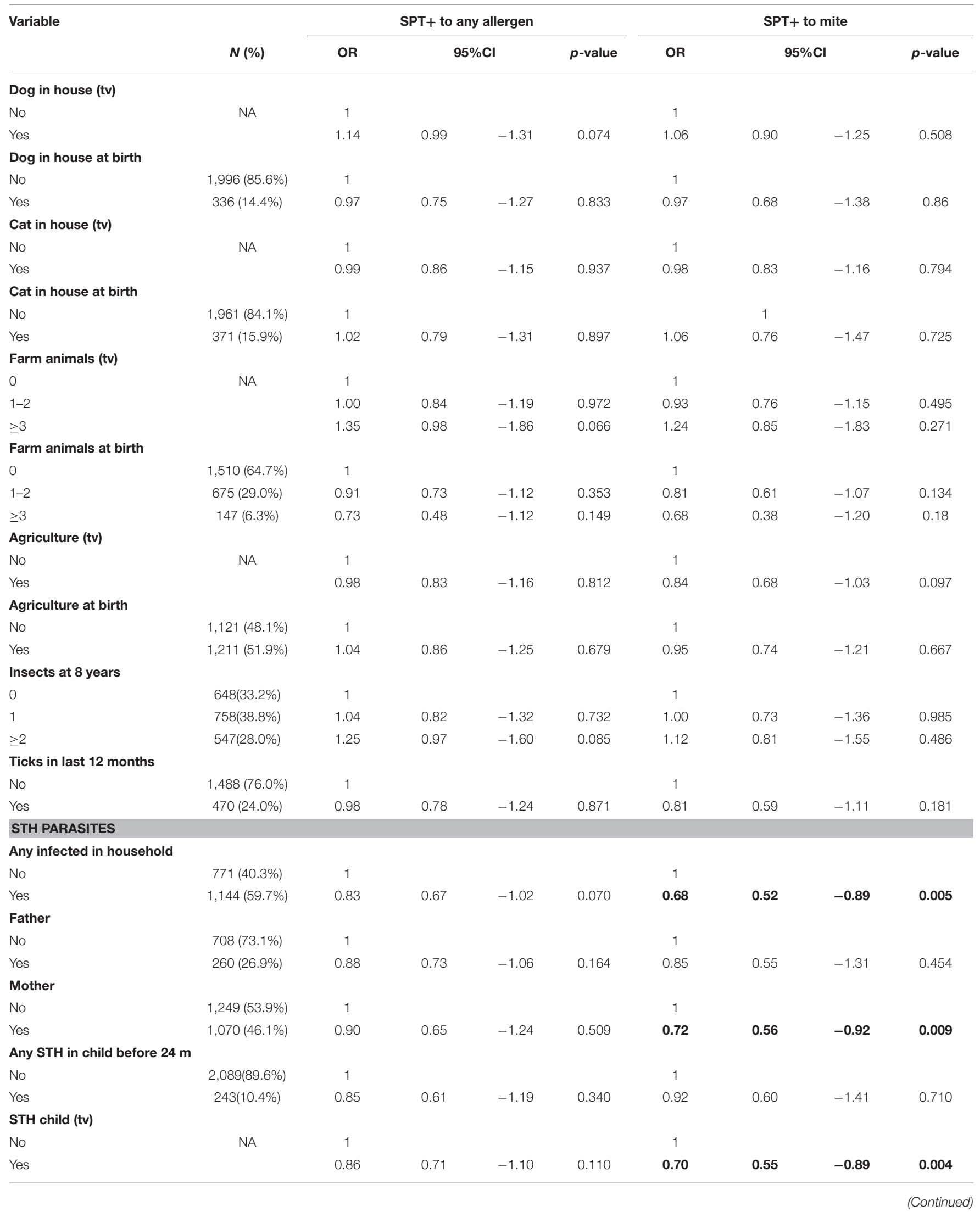


TABLE 1 | Continued

\begin{tabular}{|c|c|c|c|c|c|c|c|c|c|}
\hline \multirow[t]{2}{*}{ Variable } & \multirow[b]{2}{*}{$N(\%)$} & \multicolumn{4}{|c|}{ SPT+ to any allergen } & \multicolumn{4}{|c|}{$\mathrm{SPT}+$ to mite } \\
\hline & & OR & & & $p$-value & OR & & & $p$-value \\
\hline \multicolumn{10}{|c|}{ Anthelmintics (to $24 \mathrm{~m}$ ) } \\
\hline No & $1,506(64.6 \%)$ & 1 & & & & 1 & & & \\
\hline Yes & 826 (35.4\%) & 0.92 & 0.74 & -1.15 & 0.465 & 0.94 & 0.72 & -1.25 & 0.687 \\
\hline \multicolumn{10}{|c|}{ Anthelmintics (tv) } \\
\hline No & NA & 1 & & & & 1 & & & \\
\hline Yes & & 1.18 & 0.93 & -1.49 & 0.165 & 1.34 & 1.00 & -1.79 & 0.051 \\
\hline \multicolumn{10}{|c|}{ 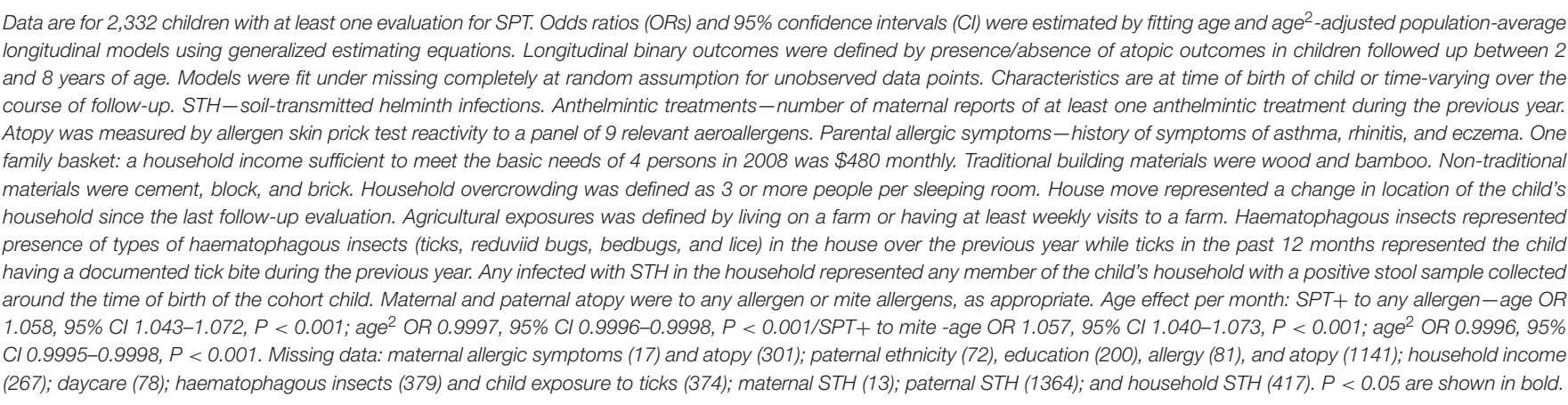 } \\
\hline
\end{tabular}

(unless otherwise specified) are shown in Table 1. Total numbers of anthelmintic treatments received by the 2,404 newborns recruited over up to 8 years of follow-up were: $0-1$ (8.1\%), 2$3(44.1 \%)$, and $\geq 4(47.8 \%)$ treatments. Parasite burdens with $A$. lumbricoides and $T$. trichiura were predominantly light with a minority having moderate or heavy infection intensities at any specific age between 7 months to 8 years (peak percentage for moderate $-35 \%$ for $A$. lumbricoides at 30 months and $17 \%$ for T. trichiura at 24 months; heavy-9\% for A. lumbricoides at 30 months and $2 \%$ for $T$. trichiura at 30 months). Proportions with allergic disease symptoms at 8 years among 1,971 children with available data were wheeze $(6.6 \%)$, eczema $(7.9 \%)$, and rhinitis (2\%).

\section{Patterns and Emergence of Allergic Sensitization in Children and Their Parents}

Percentages of children with SPT + at 8 years and their parents (2,031 mothers and 1,191 fathers) to the same 6 aeroallergens ( $D$. pteronyssinus/farinae, American cockroach, dog, cat, fungi, and grass pollens) are shown in Figure 2. Fathers had the greatest rates of sensitization to any of these allergens (29.0\%), followed by mothers $(24.8 \%)$ and cohort children (13.8\%). The dominant aeroallergens in this population were Dermatophagoides spp. and American cockroach (fathers 18.8 and $17.8 \%$, respectively; mothers 15.7 and 14.7\%; and children 10.7 and 5.3\%). Allergic sensitization among parents to other aeroallergens were: grass pollens (fathers 5.4\% and mothers 3.2\%), fungi (5.6 and $2.7 \%$ ), dogs (2.2 and 1.5\%), cats (1.3 and 1.2\%), and A. tenuis (2.6 and 1.5\%). Rates of sensitization to allergens not included in Figure 2 were to the mites $B$. tropicalis (fathers $6.6 \%$ and mothers $4.7 \%$ ) and $C$. arcuatus (6.6 and $3.9 \%$ ), and to the fungus $A$. tenuis (2.6 and $1.5 \%)$. Allergic sensitization to the 9 aero and food allergens tested in cohort children from 2 through to 8 years is shown in Figure 3: percentages of children with sensitization to any allergen was greatest at 8 years $(14.8 \%)$ and was $13.8 \%$ to perennial and $0.5 \%$ to food allergens. Significant sensitization to individual allergen extracts $(>2 \%)$ were only seen for Dermatophagoides spp. and cockroach: Dermatophagoides spp. sensitization was present at 2 years and increased rapidly while cockroach sensitization emerged later at 5 years. Proportions of children with SPT + to any allergen but without mite sensitization were $50.8 \%$ at $2,37.9 \%$ at $3,41.1 \%$ at 5 , and $27.4 \%$ at 8 years (equivalent proportions for mothers and fathers were 36.7 and $34.9 \%$, respectively). Relatively few children had sensitization to food allergens with rates of $\leq 1.3 \%$ (to any of milk, egg, and peanut) at any of the observation times. Polysensitization (sensitization to more than one allergen) increased with age: 2 years $(0.7 \%), 3$ years $(1.4 \%), 5$ years $(2.8 \%)$, and 8 years $(4.2 \%)$. Rates of polysensitization in mothers and fathers were 7.9 and $10.4 \%$, respectively.

\section{Exposures Associated With Allergic Sensitization to Any Allergen During First 8 Years of Life}

Longitudinal analyses showed that the risk of SPT + to any allergen were strongly associated with age in a non-linear fashion (Table 1 and Figure 4). Minimally age-adjusted populationaveraged and multivariable associations between child, parental, household economic, and hygiene factors and development of SPT + during the first 8 years of life are shown in Table 1. Age-adjusted models showed significant positive associations between SPT + to any allergen and maternal allergic symptoms (OR 1.62, 95\% CI 1.12-2.36) and SPT+ (OR 1.57, 95\% CI 1.27-1.93) and having a household income $>\$ 470 /$ month 


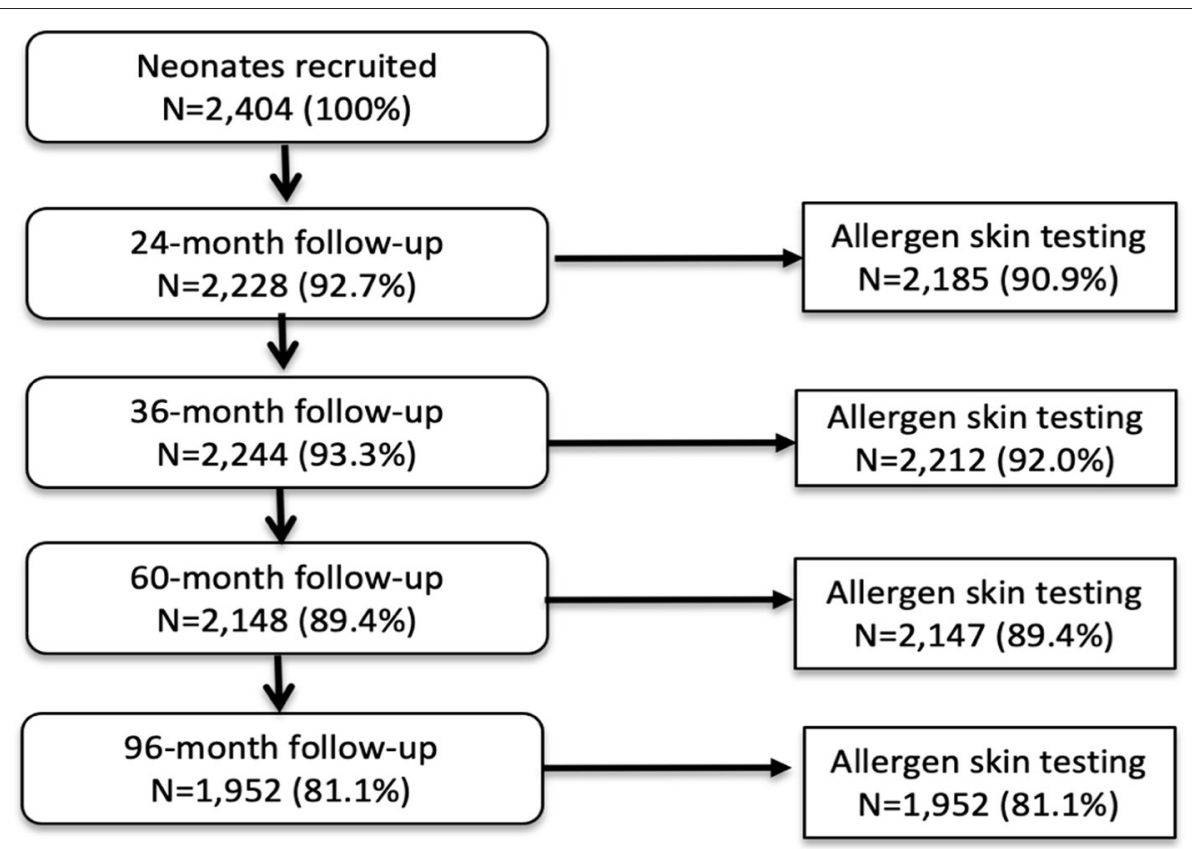

FIGURE 1 | Flow diagram to show follow-up of cohort to 8 years and allergen skin prick testing. Denominator for all proportions is 2,404. A child with any SPT result during follow-up was included in the longitudinal analysis.

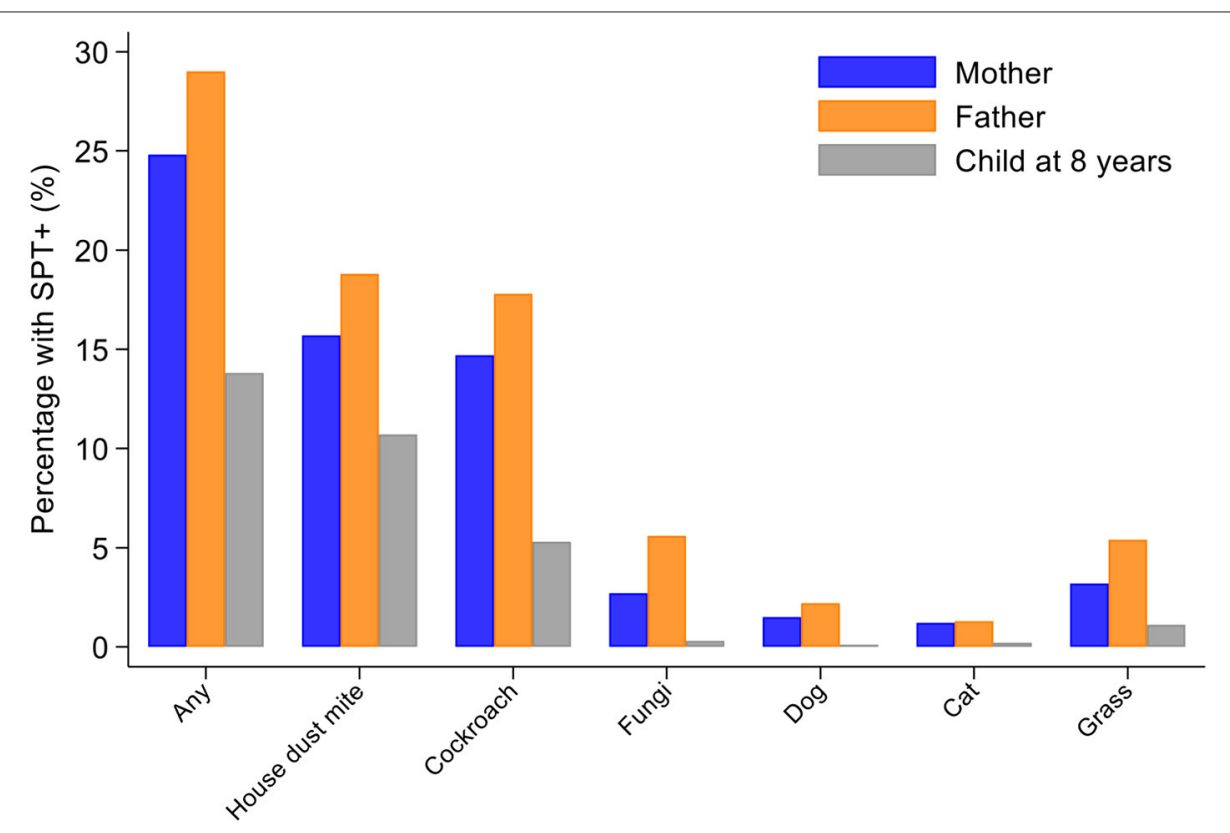

Allergies

FIGURE 2 | Percentages of mothers, fathers, and cohort children (at 8 years) with positive skin prick tests (SPT+) to any allergen and individual allergen extracts. Data for Mothers ( $n=2,031)$ (blue bars), fathers $(n=1,191)$ (orange bars), and children at 8 years $(n=1,952)$ (gray bars).

(equivalent to meeting a household's basic needs) (OR 1.48, 95\% CI 1.02-2.16). An increasing number of maternal SPT+ reactions was associated with a greater risk of childhood SPT+ to any allergen (vs. SPT-: monosensitization, OR 1.33, 95\% CI
1.03-1.72; polysensitization, OR 2.11, 95\% CI 1.55-2.87) (Table 1 and Figure 5).

In multivariable analyses (Table 2), childhood SPT + to any allergen was significantly associated with maternal allergic 


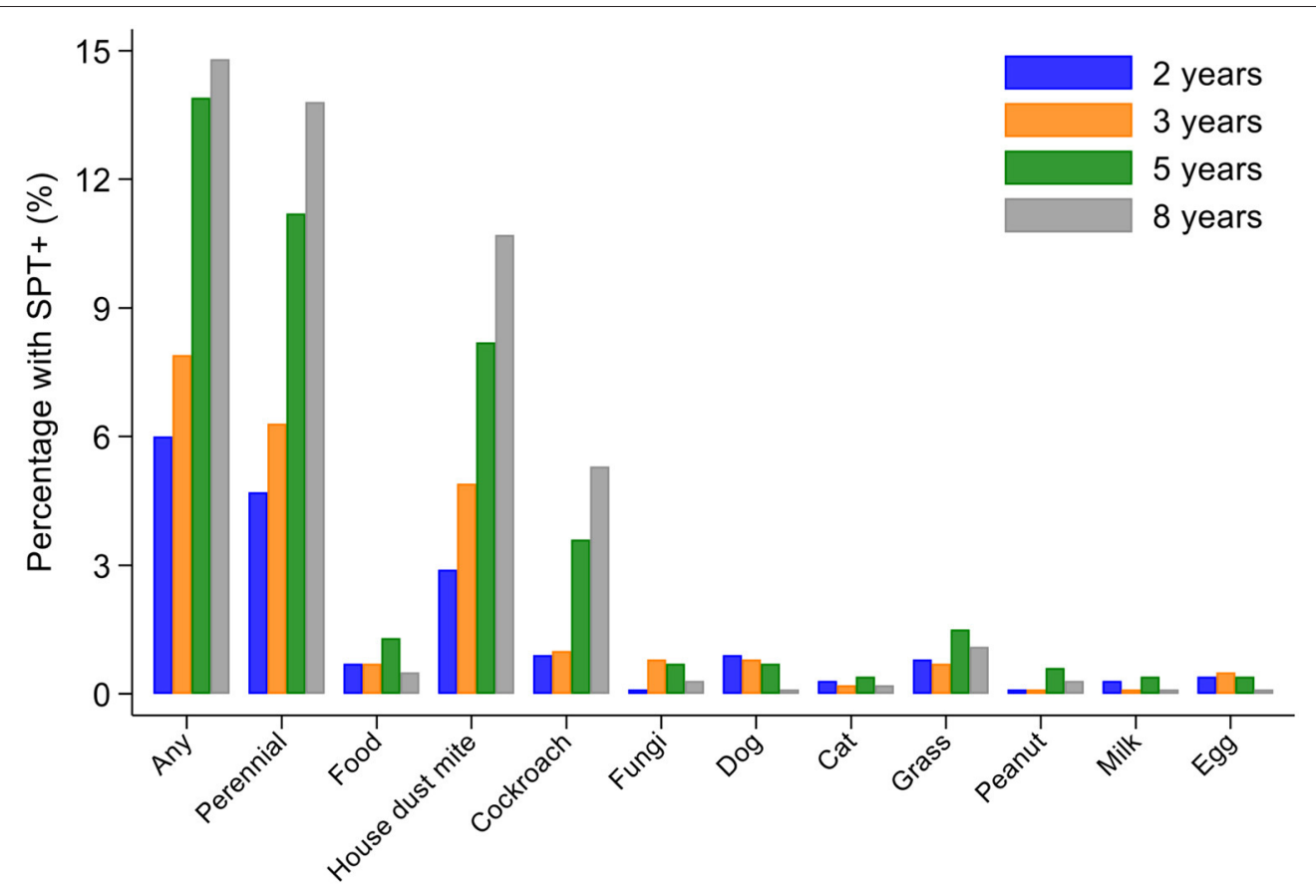

Allergies

FIGURE 3 | Changes in allergic sensitization profiles between 2 and 8 years of age in cohort. Bars represent 2 (blue), 3 (orange), 5 (gray), and 8 (yellow) years. Perennial allergens included mite, cockroach, dog, and cat allergens.

symptoms (OR 1.54, 95\% CI 1.03-2.29) and SPT+ with strong effects seen for more maternal SPT+ reactions (vs. SPT-: monosensitization, OR 1.35, 95\% CI 1.04-1.73; polysensitization, OR 2.04, 95\% CI 1.49-2.77) (Figure 5) while post-natal household overcrowding was inversely associated with SPT+ (OR 0.84, 95\% CI 0.72-0.98).

\section{Exposures Associated With Mite Sensitization During First 8 Years of Life}

Mite sensitization was strongly associated with age (Table 1 and Figure 4). Age-adjusted analyses showed significant positive associations for mite SPT + with greater maternal education status (completed secondary vs. illiterate, OR 1.70, 95\% CI 1.12-2.59), maternal mite sensitization (OR 1.68, 95\% CI 1.28-2.21) and polysensitization (vs. SPT-, OR 2.09, 95\% CI 1.40-3.11), having a greater household income (OR 1.72, 95\% CI 1.08-2.74), and living in a household constructed with non-traditional materials (OR 1.42, 95\% CI 1.04-1.93), while inverse associations were observed for greater period of breastfeeding (7-12 months vs. $\leq 6$ months, OR $0.67,95 \%$ CI 0.45-0.99), rural residence (OR 0.70, 95\% CI 0.52-0.93), being lower in the birth order (vs. 1st-2nd: 3rd-4th, OR 0.75 , 95\% CI $0.57-1.00$; $\geq 5$ th, OR 0.68 , 95\% CI 0.48-0.96), type of bathroom at time of birth (latrine vs. WC, OR 0.71 , 95\% CI 0.55-0.91), and STH infections (any household member with STH [OR 0.68, 95\% CI 0.48-0.96] maternal STH [OR 0.72, 95\% CI 0.56-0.92], and STH infections during childhood [OR $0.70,95 \%$ CI $0.55-0.89]$ ]). Interestingly, there was some evidence that anthelmintic treatments given during childhood increased the risk of mite sensitization (OR 1.34, 95\% CI 1.00-1.79).

In multivariable analyses (Table 2), mite sensitization during childhood remained significantly positively associated with greater number of maternal SPT + reactions (vs. SPT-: monosensitization OR 1.64, 95\% CI 1.17-2.29; polysensitization, OR 2.14, 95\% CI 1.40-3.27) (Figure 5) and anthelmintic treatments received during childhood (OR 1.47, 95\% CI 1.052.05 ) but inversely associated with rural residence (OR 0.69 , 95\% CI $0.50-0.94)$, birth order ( $3 \mathrm{rd}-4$ th and $\geq 5$ th vs. 1 st $-2 \mathrm{nd}$, OR 0.71), agricultural exposures (OR 0.77, 95\% CI 0.60-0.98), and STH infections acquired during childhood (OR 0.70, 95\% CI 0.64-0.91). Maternal STH were not significantly associated with SPT to any allergen or to mite in the adjusted longitudinal analyses. Analysis of effects of parasite type in age-adjusted analyses showed a protective against mite sensitization of maternal and childhood T. trichiura (maternal-OR 0.63, 95\% CI $0.44-0.90, P=0.012$; childhood-OR $0.58,95 \%$ CI $0.35-0.98$, $P=0.042$ ) and childhood A. lumbricoides (0.74, 95\% CI 0.55$0.99, P=0.042$; Figures 6, 7). There was evidence for stronger protective effects against mite SPT + of higher parasite burdens with A. lumbricoides and T. trichiura during childhood (i.e., as a time-varying exposure) although this was statistically significant only for A. lumbricoides (moderate-heavy vs. uninfected, OR 0.36, 95\% CI 0.18-0.72) (Table 3). 


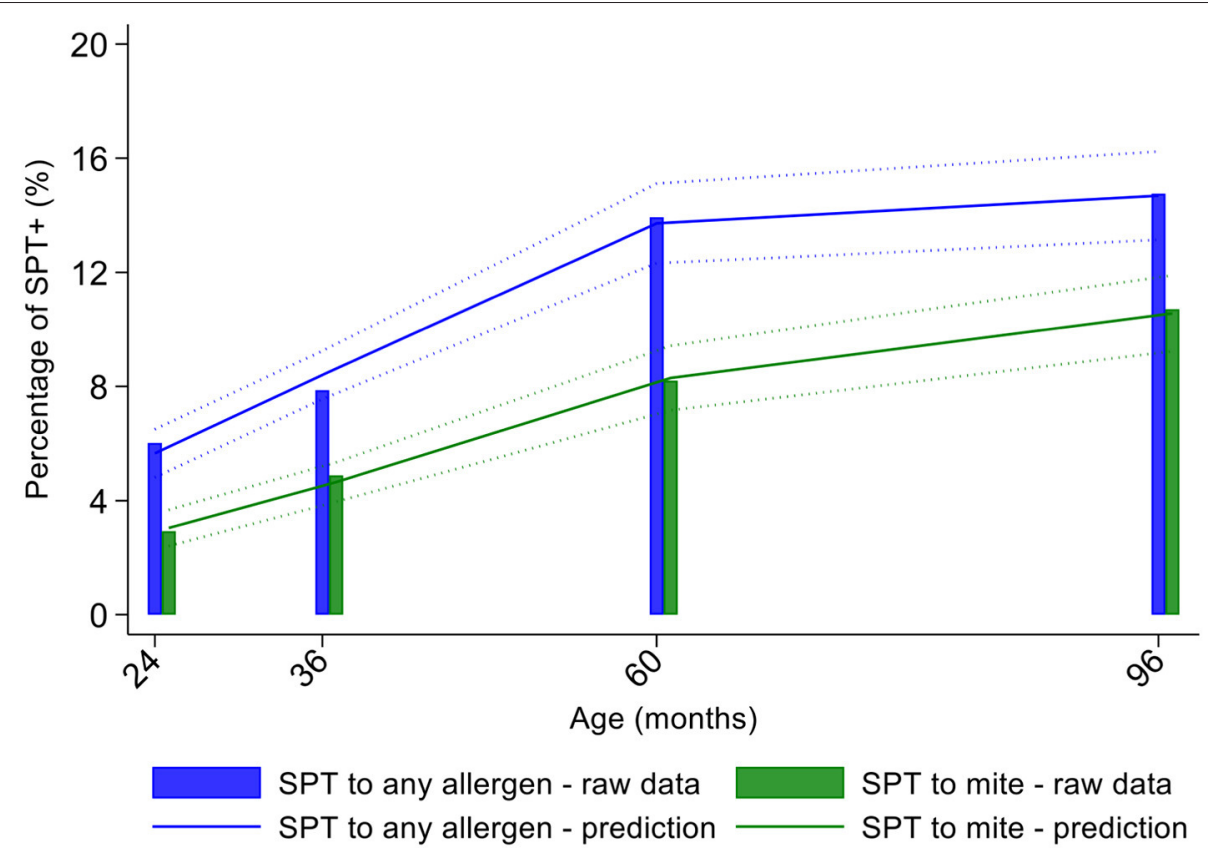

FIGURE 4 | Age-dependent proportions of cohort children with allergen skin prick test positivity (SPT+) to any allergen (blue) and to mite (green). Shown are predictions from population average longitudinal models (predictions shown by solid lines and $95 \%$ confidence intervals by dotted lines) against raw data percentages (bars).
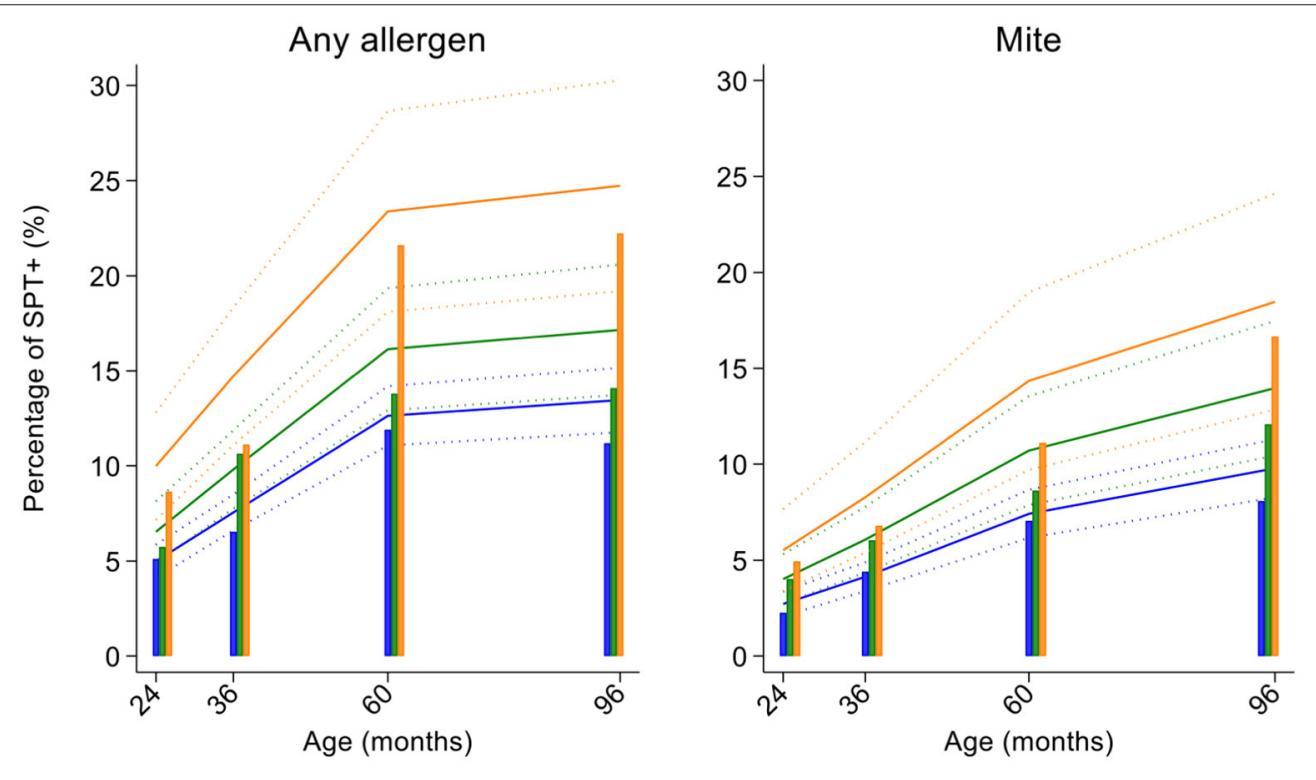

\section{Maternal sensitisations}

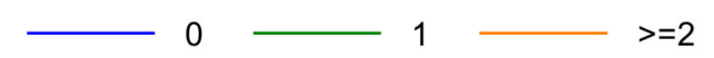

FIGURE 5 | Effects of number of maternal allergen skin prick test positive (SPT+) reactions on age-dependent proportions of cohort children with SPT+ to any allergen and to mite. Shown are predictions from population average longitudinal models (predictions shown by solid lines and $95 \%$ confidence intervals by dotted lines) against raw data percentages (bars) stratified by maternal sensitizations. Blue lines/bars -0 maternal SPT+ reactions; green lines/bars -1 SPT+ reaction; orange lines/bars - two or more SPT+ reactions. 
TABLE 2 | Multivariable associations between risk of allergen skin prick test positivity (SPT+) to any and to mite allergens during first 8 years of life and child, parental, household, and hygiene factors.

\begin{tabular}{|c|c|c|c|c|c|c|c|c|}
\hline \multirow[t]{2}{*}{ Variable } & \multicolumn{4}{|c|}{$\mathrm{SPT}+$ to any allergen } & \multicolumn{4}{|c|}{ SPT+ to mite } \\
\hline & OR & & $95 \% \mathrm{Cl}$ & $p$-value & OR & & & $p$-value \\
\hline \multicolumn{9}{|c|}{ MATERNAL FACTORS } \\
\hline \multicolumn{9}{|c|}{ Allergic symptoms } \\
\hline No & 1 & & & & & & & \\
\hline Yes & 1.54 & 1.03 & -2.29 & 0.035 & & & & \\
\hline \multicolumn{9}{|c|}{ Polysensitization } \\
\hline 0 & 1 & & & & 1 & & & \\
\hline 1 & 1.35 & 1.04 & -1.73 & 0.022 & 1.64 & 1.17 & -2.29 & 0.004 \\
\hline$\geq 2$ & 2.04 & 1.49 & -2.77 & $<0.001$ & 2.14 & 1.40 & -3.27 & $<0.001$ \\
\hline \multicolumn{9}{|c|}{ HOUSEHOLD FACTORS } \\
\hline \multicolumn{9}{|c|}{ Residence } \\
\hline Urban & & & & & 1 & & & \\
\hline Rural & & & & & 0.69 & 0.50 & -0.94 & 0.019 \\
\hline \multicolumn{9}{|c|}{ HYGIENE FACTORS } \\
\hline \multicolumn{9}{|c|}{ Birth order } \\
\hline 1 st-2nd & & & & & 1 & & & \\
\hline $3 r d-4$ th & & & & & 0.71 & 0.52 & -0.98 & 0.036 \\
\hline$\geq 5$ th & & & & & 0.71 & 0.49 & -1.05 & 0.085 \\
\hline \multicolumn{9}{|c|}{ Crowding (tv) } \\
\hline No & 1 & & & & & & & \\
\hline Yes & 0.84 & 0.72 & -0.98 & 0.032 & & & & \\
\hline \multicolumn{9}{|c|}{ Agriculture (tv) } \\
\hline No & & & & & 1 & & & \\
\hline Yes & & & & & 0.77 & 0.60 & -0.98 & 0.035 \\
\hline \multicolumn{9}{|c|}{ STH PARASITE } \\
\hline \multicolumn{9}{|c|}{ STH child (tv) } \\
\hline No & & & & & 1 & & & \\
\hline Yes & & & & & 0.70 & 0.64 & -0.91 & 0.008 \\
\hline \multicolumn{9}{|c|}{ Anthelmintics (tv) } \\
\hline No & & & & & 1 & & & \\
\hline Yes & & & & & 1.47 & 1.05 & -2.05 & 0.024 \\
\hline
\end{tabular}

Population average multivariable models were fitted to the binary longitudinal outcomes defined by presence/absence of SPT+ in children followed up between 2 and 8 years of age.

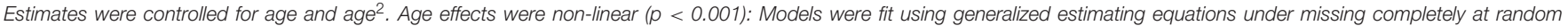
assumption for unobserved data points. OR, odds ratio; 95\% Cl, 95\% confidence intervals; STH, soil-transmitted helminth; tv, time-varying covariates.

\section{DISCUSSION}

In the present analysis, we followed up a birth cohort to 8 years of age in a tropical coastal region of Ecuador to describe patterns and emergence of allergic sensitization in parents and offspring and identify antenatal and postnatal individual and environmental factors that might affect allergic sensitization. Significant proportions of parents had allergic sensitization, mainly to arthropod allergens from mites and cockroaches, while proportions of children with allergic sensitization increased progressively with age, initially to mite but later to cockroach. Rates of sensitization to pollens, pets, fungi, and foods, remained consistently low during childhood. Of the factors we were able to study as potentially associated with allergic sensitization in childhood, maternal atopy was the most important risk factor while protective effects were associated with rural residence, agricultural exposures, and childhood STH infections.

A strength of the study was the prospective design and high rates of adherence to follow-up to 8 years of age of a population-based sample. The longitudinal design allowed us to do a repeated-measures longitudinal analysis for the outcomes (measured at 4 time-points) that estimated agedependent risk of SPT + in childhood and took into account also time-varying changes in some key environmental exposures such as childhood STH infections. Longitudinal analyses are more informative because they predict the risk of SPT + at each time point during follow-up, providing an overall agedependent risk, and insights into the dynamics of SPT + risk by age during childhood in a manner not possible when outcomes are evaluated at a single point in time. Key outcomes (SPT+) and exposures (STH infections) were measured objectively thus 

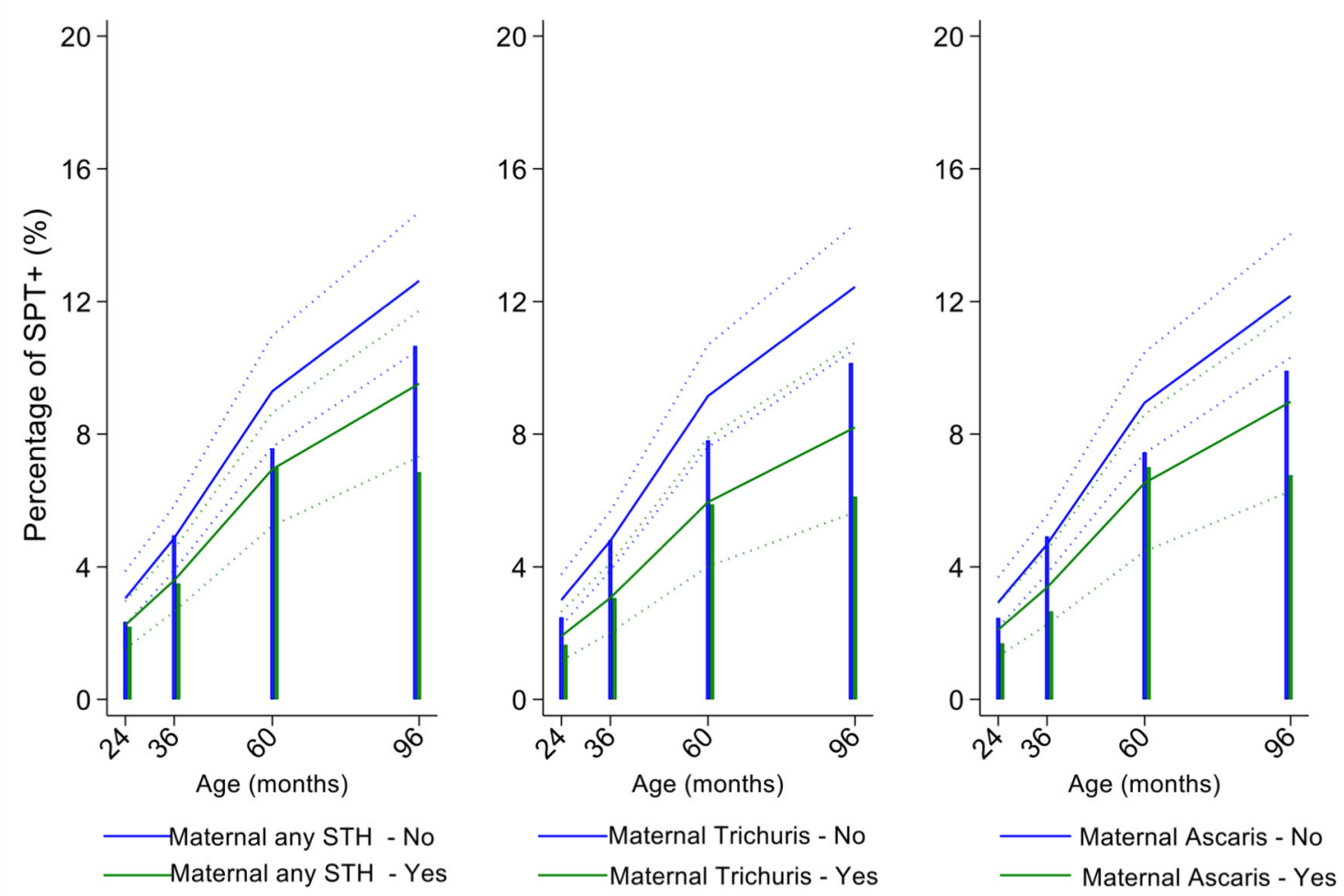

FIGURE 6 | Effect of maternal infections with any soil-transmitted helminth (STH) parasites or with specific STH species on age-dependent proportions of cohort children with allergen skin prick test positivity (SPT+) to mite. Shown are predictions from population average longitudinal models (predictions shown by solid lines and $95 \%$ confidence intervals by dotted lines) against raw data percentages (bars). Blue lines/bars - children of uninfected mothers; green lines/bars - children of infected mothers.

minimizing any potential systematic measurement bias. Recall bias is unlikely for risk factor data collected by questionnaire soon after birth for outcomes measured from 2 years of age. We were able collect data on a wide range of potential environmental exposures and potential confounders but cannot rule out potential confounding by unmeasured confounders such as maternal diet during pregnancy. We measured SPT+ to allergens selected as most relevant based on the findings of previous studies done in similar populations in coastal tropical Ecuador (22-24). It is quite possible, by inclusion of a limited panel of allergens, that we underestimated SPT + in this population. For example, we did not measure SPT + to B. tropicalis although a previous study of asthmatic children in the same province showed a much lower rate of SPT+ to $B$. tropicalis than to Dermatophagoides spp. (25). We were unable to measure SPT + to pollens largely because of a lack of commercially available and geographically appropriate pollen allergen extracts for the South American region. It has been suggested that clinically relevant pollen sensitization may be less frequent in tropical and subtropical areas than more temperate climates (26). We measured allergen sensitization or atopy using allergen skin prick test positivity rather than measurement of specific IgE. The two measures of atopy are strongly correlated in high-income countries but tend to be dissociated in poorer populations living in low and middle-income countries
(27-30), particularly where exposures to parasites such as the soil-transmitted helminth, A. lumbricoides, are common (6). Helminth parasite infections induce IgE responses to a wide variety of protein and carbohydrate molecules that cross-react extensively with allergens from multiple sources (31-33). Thus, IgE from helminth-infected individuals crossreact extensively with serological assays to detect allergens and allergen components resulting in common false-positive reactions $(29,30,34)$. While it is clear that allergen-specific IgE at high titer from such individuals is strongly associated with allergic symptoms such as asthma (35), the relationship with low titer IgE where most of the IgE-allergen reactivity is seen, is less clear. For this reason, the use of allergen $\mathrm{SPT}+$ is preferable for measuring allergic sensitization in populations living in tropical regions where helminth infections are endemic (30).

We used a birth cohort to define the emergence and development of allergic sensitization during early childhood to school age and measured atopy in parents to estimate rates of atopy in adults. Fathers had the highest rates of atopy (fathers $29 \%$ vs. mothers $24.8 \%$ ) with similar rates of sensitization to mite (D. pteronyssinus and D. farinae, 18.8\%) and American cockroach (17.8\%), and lower rates of sensitization to pollens, fungi, and pets. Patterns were similar in mothers albeit at lower rates. Such patterns of allergic sensitization are consistent with previous 

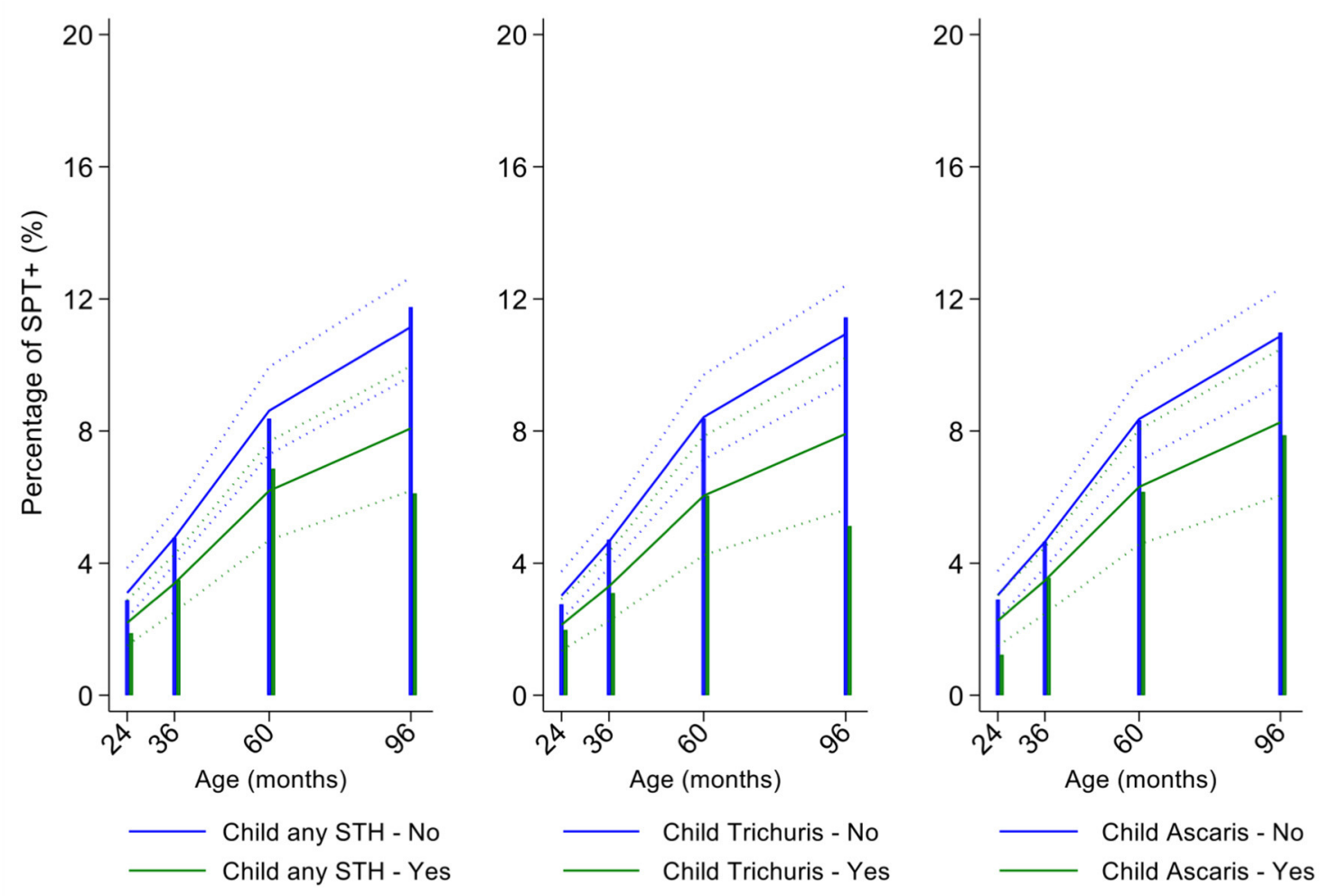

FIGURE 7 | Effect of childhood soil-transmitted helminth (STH) parasites or with specific STH species on age-dependent proportions of cohort children with allergen skin prick test positivity (SPT+) to mite. Shown are predictions from population average longitudinal models (predictions shown by solid lines and 95\% confidence intervals by dotted lines) against raw data percentages (bars). Blue lines/bars - uninfected children; green lines/bars -infected children.

data from tropical urban environments (36-38). We saw much lower rates of sensitization $(<7 \%)$ to the tropical mite, Blomia tropicalis, and the storage mite Chortoglyphus arcuatus compared to Dermatophagoides spp. B. tropicalis is an important source of allergens in tropical and subtropical settings and has been associated with respiratory allergies $(6,38)$, atopic dermatitis, and food allergies (39). Mite fauna in house dust samples from tropical settings including Ecuador are highly diverse $(6,40,41)$ and vary geographically between such settings (6). The storage mite $C$. arcuatus has been reported in house dust samples from tropical Latin America $(41,42)$ where sensitization to this mite was observed in patients with asthma $(41,43)$ and allergic rhinitis (41). In this birth cohort, we observed early sensitization to Dermatophagoides spp. mites in $2.9 \%$ of children by 2 years of age, a rate that increased progressively to $10.7 \%$ at 8 years. Cockroach sensitization emerged at 5 years while sensitizations to other aeroallergens were negligible (i.e., $<2 \%$ ). The early emergence of mite sensitization in tropical settings could "drive" international comparisons of atopy, particularly if sensitization to other allergens emerged later in the life course. A bias toward sensitization to invertebrate allergens in early childhood in such a setting is perhaps not surprising given the tendency of children, living in conditions of poverty in precarious circumstances, to spend more time indoors in microenvironments that are increasingly sealed off from much of the animal and plant world and that, in the humidity and heat of the tropics, provide ideal conditions for the proliferation of mites and cockroaches that themselves produce allergens with a proclivity to become airborne. Polysensitization was relatively infrequent in both children $(4.2 \%$ at 8 years $)$ and parents $(<11 \%)$. It should be remembered that this was an unselected populationbased cohort with no enrichment for children (or parents) with allergic diseases and thus provides data on rates of sensitization in the general population.

A predominance of SPT + to mite and cockroach allergens has been observed previously in cohorts of young children from tropical regions: (1) a study of 878 children aged 3 years in Ethiopia observed $8.7 \%$ positivity to any allergen $(5.6 \%$ mite and $4.2 \%$ cockroach) (44); (2) a study of 132 young Indonesian children showed $19 \%$ had positive skin tests to any allergen at 4 years $(10 \%$ cockroach and $7 \%$ mite) while very few $(0.8 \%)$ had positive tests to food allergens (45); (3) a study of 1,170 children followed up to 9 years in Uganda with a subsample of 569 children tested at 3 years showed a positivity at 3 years of $18 \%$ to any allergen (Dermatophagoides spp. 11\%, Blomia tropicalis 12\%) and at 9 years of $25 \%$ to any allergen (Dermatophagoides spp. $18 \%$, B. tropicalis $15 \%$ ), and cockroach $12 \%$ with low positivity rates $[<1.5 \%$ ] to cat, molds, pollens, and food allergens [peanut, egg, and milk] (7); a study of 244 children aged $2-3$ years in Colombia showed SPT + to any allergen to be $22 \%(12 \% B$. 


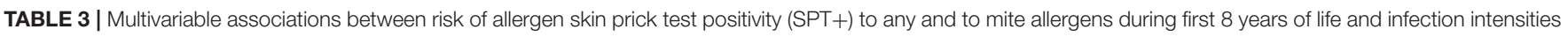
with A. lumbricoides and T. trichiura.

\begin{tabular}{|c|c|c|c|c|c|c|}
\hline \multirow[t]{2}{*}{ STH parasite } & \multicolumn{3}{|c|}{ SPT+ to any allergen } & \multicolumn{3}{|c|}{ SPT+ to mite } \\
\hline & OR & $95 \% \mathrm{Cl}$ & $p$-value & OR & $95 \% \mathrm{Cl}$ & $p$-value \\
\hline \multicolumn{7}{|l|}{ A. lumbricoides } \\
\hline Uninfected & 1 & & & 1 & & \\
\hline Light & 0.87 & $0.67-1.14$ & 0.319 & 0.80 & $0.58-1.10$ & 0.176 \\
\hline Moderate/heavy & 0.78 & $0.51-1.17$ & 0.229 & 0.36 & $0.18-0.72$ & 0.004 \\
\hline \multicolumn{7}{|l|}{ T. trichiura } \\
\hline Uninfected & 1 & & & 1 & & \\
\hline Light & 0.90 & $0.70-1.16$ & 0.402 & 0.78 & $0.57-1.07$ & 0.129 \\
\hline Moderate/heavy & 1.07 & $0.61-1.91$ & 0.807 & 0.38 & $0.13-1.11$ & 0.077 \\
\hline
\end{tabular}

Population average multivariable models were fitted to the binary longitudinal outcomes defined by presence/absence of SPT+ in children followed up between 2 and 8 years of age.

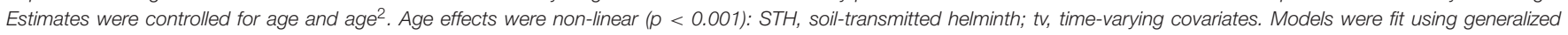

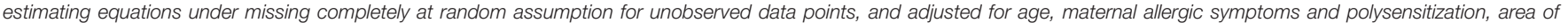

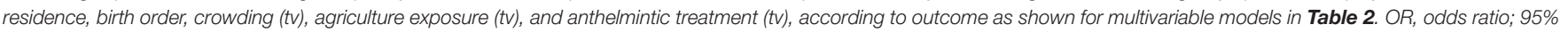

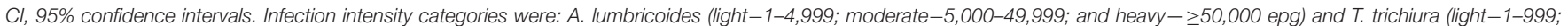
moderate-1000-9,999; and heavy $-\geq 10,000$ epg). $P<0.05$ are shown in bold.

tropicalis, $4 \%$ D. pteronyssinus, $2 \%$ cockroach, $5 \%$ cat, and $4 \%$ dog) while at 6 years SPT+ was $9 \%$ to B. tropicalis, $8 \%$ to $D$. pteronyssinus, $5 \%$ to cockroach, and $<1.2 \%$ to cat and $\operatorname{dog}(8)$. As for the present study, the latter two studies showed the early emergence of mite sensitization and a low rate of sensitization to food allergens. There are relatively few studies of food allergy from tropical and sub-tropical regions of low and middle-income countries (LMICs) and there is a perception that food allergy is less frequent in LMICs compared to high-income countries, although current data are considered inadequate for systematic reviews of food allergy risk in LMICs $(46,47)$.

Previous cross-sectional studies done in pre-school and school age children in Ecuador have shown the following: (1) analysis of urban and rural schoolchildren in tropical regions of Esmeraldas Province showed prevalence of SPT + to any allergen of $10.0 \%$ (7.6\% to mite and $2.2 \%$ to cockroach) in urban and $12.5 \%(6.8 \%$ to mite and $4.5 \%$ to cockroach) in rural areas (24); (2) analyses of rural school children in sub-tropical and tropical areas of Pichincha Province showed prevalence of SPT + to any allergen of $20-24.0 \%$ (mite, 9.3-8.0\%; cockroach 9.4-15\%) in different samples $(22,23)$; (3) analysis of urban and rural schoolchildren in highland Ecuador (altitude $>1,500 \mathrm{~m}$ ) showed SPT+ to any allergen of $52.6 \%$ ( $42.1 \%$ to mite and $19.4 \%$ to cockroach) in urban and $55.9 \%$ (43.4\% to mite and $28.4 \%$ to cockroach) in rural samples (48); (4) analysis of pre-school children aged $3-5$ years in city of Cuenca in a highland region $(>2,000 \mathrm{~m}$ altitude) showed SPT + to any allergen of $33.5 \%$ (24.3\% to mite and $2.6 \%$ to cockroach) (49); and analysis of schoolchildren in Quito in a highland region (altitude 2,800 m) aged 6-21 years showed SPT + to any allergen of $34.4 \%$ (34.1\% to mite) (50). National studies in samples of children have shown, therefore, a predominance of positivity to mite and cockroach allergens using highly standardized extracts from reputable suppliers (ALK, Greer, and Leti) indicating the importance of sensitization to arthropod allergens. Further, SPT + was much greater in higher altitude areas of the country (i.e., $>1,500 \mathrm{~m}$ where climate can vary from sub-tropical to more temperate) than tropical regions of the country despite climatic conditions in tropical areas favoring greater exposures to arthropod-derived allergens. However, significant densities of mites and concentrations of mite allergens have been observed in highland settings such as Quito where humidity is sufficient to support mite growth (41). Such geographic differences in rates of SPT + are unlikely to be explained by regional differences in ethnicity given a greater level of African genetic admixture in coastal populations that might increase risk $(51,52)$. A more plausible explanation is differences in key allergy-modifying environmental factors. An exposure that is consistently greater in tropical and sub-tropical regions of the country is STH parasite infections that thrive in the warm and moist conditions in tropical areas of the country (53). STH infections have been shown consistently to be inversely associated with SPT + in different populations in tropical and sub-tropical regions of coastal Ecuador (adjusted ORs varying $0.62-0.78$ between different studies) (22-24). These observations point to the fact that socio-environmental factors are likely to be more important risk factors for allergic sensitization than allergen-specific factors such as dosage or timing of exposure.

In this analysis, we focussed largely on the role of factors relating to poor hygiene as potential determinants of the expression of allergic sensitization. The only factor that was significantly associated with a reduced risk of SPT + to any allergen during the first 8 years of life was household overcrowding as observed previously in a cross-sectional analysis in schoolchildren from a neighboring district (24). Overcrowding could mediate a protective effect against allergic sensitization through increased risk of childhood infections or a more diverse microbiome (54). Environmental factors protective against mite sensitization in the longitudinal analyses included rural residence, birth order, agricultural exposures (defined by living on farm or at least weekly visits to a farm), and childhood infections with STH. Rural residence and farming exposures have been consistently shown to protect against allergic sensitization 
in a wide variety of settings (55) and may mediate their effects through exposure to more biodiverse environments that provide strong immune regulatory signals (56) during the first 1,000 days of life. The effect of agricultural exposures was dependent on the presence of the exposure during childhood (i.e., time-varying variable) indicating active modulation of SPT + .

Similarly, childhood STH were significantly protective when present early in the life course with stronger effects observed for T. trichiura than for A. lumbricoides. These results are consistent with a previous analysis from this cohort of the effects of early life STH exposures on the presence of SPT + to any allergen at 8 years of age (i.e., an analysis that ignored the effects of age on the acquisition of SPT+) in which protective effects were observed among children of STH-infected mothers. In the previous analysis, strongest protective effects against SPT+ at 8 years were seen among children with STH infections during the first 5 years of life who also had infected mothers (11). Here, using an analysis that estimated age-dependent risk of SPT+ rather than at a single point in time, we observed a significant protective effect of maternal infections with $T$. trichiura against mite SPT+ over the first 8 years of life. Further, we observed an effect of STH infections acquired during childhood (i.e., as a time-varying exposure) on mite SPT+ with the strongest protective effects being present in children acquiring T. trichiura infections who also had infected mothers. These findings could indicate evidence for an antenatal effect of maternal $T$. trichiura in reducing age-dependent risk of mite SPT + but which required infections during childhood to maintain the effect. Potentially, maternal T. trichiura infections could induce in utero modulation of the Th2 immune response of the developing fetus such that the capacity for allergic sensitization in offspring is reduced with infections acquired during post-natal life reinforcing such modulatory effects. We have shown previously that maternal STH can sensitize the fetus to STH antigens (57) and the type of sensitization induced (e.g., for greater immune reactivity or tolerization) is likely determined by the nature of the maternal immune response to that parasite $(45,58)$. Detection of a specific effect on mite $\mathrm{SPT}+$ may relate to the fact that this is the dominant sensitizing allergen in early childhood in this population and to the extensive immunological cross-reactivity between STH and mite allergens (e.g., tropomyosin, paramyosin, and glutathione-S-transferase) (6) that could cross-modulate parasite-mite allergen-induced immediate hypersensitivity responses (32).

Anthelmintic treatments given during childhood (i.e., a time-varying exposure) increased the risk of mite sensitization supporting a role for childhood STH infections, acquired in early childhood, in the active suppression of mite SPT + . We have shown previously: (1) in a cluster-randomized trial of albendazole given every 2 months to schoolchildren over a period of 12 months that anthelmintic treatment had no effect on SPT+ prevalence (23); and (2) in an observational study of the impact of a mass drug administration programme using the broad-spectrum anthelmintic drug ivermectin to eliminate onchocerciasis, that children living in intervention communities had a greater prevalence of SPT + , an effect that was explained best by a lower prevalence of $T$. trichiura (59). In the latter study, anthelmintic treatments had been started before the study children were born in intervention communities implying that a reduction in maternal STH infections or transmission in early life (but not at school-age) are critical for mediating the protective effects of STH against SPT+.

We observed a strong association between maternal but not paternal atopy on the development of allergic sensitization during childhood with stronger maternal effects observed with greater number of sensitizing allergens. Previous studies have shown parental history of atopic diseases to be a risk factor for allergic outcomes in offspring $(60,61)$. There are more limited published data on effects of parental allergic sensitization on sensitization in offspring. A study in Germany showed that maternal but not paternal SPT+ was associated with allergic sensitization in children aged 7-16 years (62). Maternal SPT + could increase the risk of atopy in offspring through increased genetic risk, intra-uterine factors, and other maternal factors such as diet. Although heritability of allergen SPT + has been estimated at $35 \%$, findings of genome-wide association studies for this trait showed no specific associations and indicated that genetic effects were likely mediated through a large number of different genes each contributing only a small risk (63). The effect of maternal but not paternal atopy is less suggestive of genetic or shared environment than specific intra-uterine effects. Children can be sensitized to allergens in utero (64) and our data suggest that maternal SPT+, particularly multiple sensitizations (taken as a measure of greater propensity to atopy), may alter how a child's immune response is programmed to react to allergens during the process of immune development and maturation in early childhood. Such effects could also be mediated through epigenetic mechanisms induced by environmental triggers (e.g., maternal nutrition) occurring during limited time frames in utero and early postnatal life (65).

In conclusion, there are limited data from birth cohorts in populations in tropical regions of low and middleincome countries studying the natural history of allergen sensitization and the individual and environmental risk factors for sensitization early in the life course. Here, we followed up a birth cohort to 8 years of age showing that the dominant sensitizing allergens present in this tropical setting are those relating to arthropods, specifically mite (more D. pteronyssinus than $B$. tropicalis) and cockroach, and mite sensitization emerges earliest and predominates to school age. Our data showed a role for both antenatal and post-natal factors in determining the emergence of allergic sensitization in offspring. Maternal SPT + increased a child's risk of SPT + to any allergen indicating the importance of in utero factors in determining a child's longterm risk of atopy. Childhood STH infections and agricultural exposures played an important role in modifying the risk of mite sensitization post-natally even after controlling for maternal atopy. Our data were from a population-based sample and the findings are generalizable to similar populations of children living in rural settings in tropical areas of Latin America. Future prospective studies in tropical LMIC settings could usefully explore the causal link between the acquisition of allergen sensitization and the development of allergic diseases during childhood and how individual and environmental factors modify this link. 


\section{DATA AVAILABILITY STATEMENT}

The raw data supporting the conclusions of this article will be made available by the authors, without undue reservation.

\section{ETHICS STATEMENT}

The studies involving human participants were reviewed and approved by the ethics committees of Hospital Pedro Vicente Maldonado, Pedro Vicente Maldonado, Pichincha Providence; and Universidad San Francisco de Quito, Quito, Ecuador. Written informed consent to participate in this study was provided by the participants' legal guardian/next of kin.

\section{AUTHOR CONTRIBUTIONS}

PC conceived, designed, supervised the study, and drafted the manuscript. $\mathrm{MB}$ and DS provided important input to study

\section{REFERENCES}

1. Burbank AJ, Sood AK, Kesic MJ, Peden DB, Hernandez ML. Environmental determinants of allergy and asthma in early life. J Allergy Clin Immunol. (2017) 140:1-12. doi: 10.1016/j.jaci.2017.05.010

2. Weinmayr G, Genuneit J, Nagel G, Bjorksten B, van Hage M, Priftanji $\mathrm{A}$, et al. International variations in associations of allergic markers and diseases in children; ISAAC phase II. Allergy. (2000) 65:76675. doi: 10.1111/j.1398-9995.2009.02283.x

3. Bousquet PJ, Castelli C, Daures JP, Heinrich J, Hooper R, Sunyer J, et al. Assessment of allergen sensitization in a general population-based survey (European Community Respiratory Health Survey I). Ann Epidemiol. (2010) 20:797-803. doi: 10.1016/j.annepidem.2010.05.012

4. Charpin D, Ramadour M, Lavaud F, Raherison C, Caillaud D, de Blay F, et al. Climate and allergic sensitization to airborne allergens in the general population: data from the French six cities study. Int Arch Allergy Immunol. (2017) 172:236-41. doi: 10.1159/000471511

5. Weinmayr G, Weiland SK, Björkstén B, Brunekreef B, Büchele G, Cookson WO, et al. Atopic sensitization and the international variation of asthma symptom prevalence in children. Am J Respir Crit Care Med. (2007) 176:56574. doi: 10.1164/rccm.200607-994OC

6. Caraballo L, Zakzuk J, Lee BW, Acevedo N, Soh JY, Sánchez-Borges M, et al. Particularities of allergy in the tropics. World Allergy Organ J. (2016) 9:20. doi: 10.1186/s40413-016-0110-7

7. Lule SA, Mpairwe H, Nampijja M, Akello F, Kabagenyi J, Namara B, et al. Life-course of atopy and allergy-related disease events in tropical subSaharan Africa: a birth cohort study. Pediatr Allergy Immunol. (2017) 28:37783. doi: 10.1111/pai.12719

8. Zakzuk J, Mercado D, Bornacelly A, Sánchez J, Ahumada V, Acevedo N, et al. Hygienic conditions influence sensitization to Blomia tropicalis allergenic components: results from the FRAAT birth cohort. Pediatr Allergy Immunol. (2019) 30:172-8. doi: 10.1111/pai.13004

9. Cooper PJ, Chico ME, Amorim L, Sandoval C, Vaca M, Strina A, et al. Effects of maternal geohelminth infections on allergy in childhood. J Allergy Clin Immunol. (2016) 137:899-906. doi: 10.1016/j.jaci.2015.07.044

10. Cooper PJ, Chico ME, Vaca MG, Sandoval CA, Loor S, Amorim L, et al. Effect of early life geohelminth infections on the development of wheezing at 5 years of age. Am J Respir Crit Care Med. (2018) 197:36472. doi: 10.1164/rccm.201706-1222OC

11. Cooper P, Chis Ster I, Chico ME, Vaca M, Oviedo Y, Maldonado A, et al. Impact of early life geohelminths on wheeze, asthma, and atopy in Ecuadorian children at 8 years. Allergy. (2021). doi: 10.1111/all.14821. [Epub ahead of print]. design and conduct. MC and MV were responsible for data collection. IC did the statistical analysis. All authors reviewed the manuscript critically before submission.

\section{FUNDING}

This study was funded by the Wellcome Trust (grant 088862/Z/09/Z).

\section{ACKNOWLEDGMENTS}

We thank the ECUAVIDA cohort study team for their dedicated work and the cohort mothers and children for their enthusiastic participation. We acknowledge also the support of the Directors and staff of the Hospital Padre Alberto Buffoni in Quininde, Esmeraldas Province. The study forms part of the SCAALA (Social Changes, Asthma, and Allergies in Latin America) programme of research.

12. Cooper PJ, Chico ME, Platts-Mills TAE, Rodrigues LC, Strachan DP, Barreto ML. Cohort profile: the ecuador life (ECUAVIDA) study in Esmeraldas province, Ecuador. Int $J$ Epidemiol. (2015) 44:1517-27. doi: 10.1093/ije/dyu128

13. Calvopiña M. Terapéutica antiparasitaria. Ministerio de Salud Pública del Ecuador, Ecuador. 2nd Ed. Quito: Noción (1997).

14. World Health Organization. Diagnostic Techniques for Intestinal Parasitic Infections (IPI) Applicable to Primary Health Care (PHC) Services. WHO: Geneva (1985).

15. Cooper PJ, Chico ME, Guadalupe I, Sandoval CA, Mitre E, Platts-Mills TA, et al. Impact of early life exposures to geohelminth infections on the development of vaccine immunity, allergic sensitization, and allergic inflammatory diseases in children living in tropical Ecuador: the ECUAVIDA birth cohort study. BMC Infect Dis. (2011) 11:184. doi: 10.1186/1471-2334-11-184

16. Goldstein H. Multilevel Statistical Models, Wiley Series in Probability and Statistics. 4th Ed. Chichester: Wiley (2011). doi: 10.1002/97804709 73394

17. Fitzmaurice G, Davidian M, Verbeke G, Molenberghs G. Longitudinal Data Analysis. Boca Raton, FL: Chapman and Hall/CRC (2008). doi: 10.1201/9781420011579

18. Szmaragd C, Clarke P, Steele P. Subject specific and population average models for binary longitudinal data: a tutorial. Longitud Life Course Stud. (2013) 4:147-65. doi: 10.14301/llcs.v4i2.249

19. Pan W. Akaike's information criterion in generalized estimating equations, Biometrics. (2001) 57:120-5. doi: 10.1111/j.0006-341X.2001.00120.x

20. Cui J. QIC program and model selection in GEE analyses. Stata J. (2007) 7:209-20 doi: 10.1177/1536867X0700700205

21. Little RJA, Rubin DB. Statistical Analysis with Missing Data, Wiley Series in Probability and Statistics. 2nd Ed. Chichester: Wiley (2014).

22. Cooper PJ, Chico ME, Griffin GE, Nutman TB. Allergy symptoms, atopy, and geohelminth infections in a rural area of Ecuador. Am J Resp Crit Care Med. (2003) 168:313-7. doi: 10.1164/rccm.200211-1320OC

23. Cooper PJ, Chico ME, Vaca M, Moncayo AL, Bland M, Rodrigues L, et al. Impact of bimonthly treatment of geohelminth-infected children with albendazole on atopy prevalence: a cluster-randomized trial. Lancet. (2006) 367:1598-603. doi: 10.1016/S0140-6736(06)68697-2

24. Cooper PJ, Vaca M, Rodriguez A, Chico ME, Santos DN, Rodrigues LC, et al. Hygiene, atopy and wheeze-eczema-rhinitis symptoms in schoolchildren from urban and rural Ecuador. Thorax. (2014) 69:2329. doi: 10.1136/thoraxjnl-2013-203818

25. Ardura-Garcia C, Vaca M, Oviedo G, Sandoval C, Workman L, Schuyler AJ, et al. Risk factors for acute asthma in tropical America: a case-control 
study in the City of Esmeraldas, Ecuador. Pediatr Allergy Immunol. (2015) 26:423-30. doi: 10.1111/pai.12401

26. Cabauatan CR, Lupinek C, Scheiblhofer S, Weiss R, Focke-Tejkl M, Bhalla $\mathrm{PL}$, et al. Allergen microarray detects high prevalence of asymptomatic IgE sensitizations to tropical pollen-derived carbohydrates. J Allergy Clin Immunol. (2014) 133:910-4.e5. doi: 10.1016/j.jaci.2013.10.004

27. Moncayo AL, Vaca M, Oviedo G, Workman LJ, Chico ME, Platts-Mills TA, et al. Effects of geohelminth infection and age on the associations between allergen-specific IgE, skin test reactivity and wheeze: a case-control study. Clin Exp Allergy. (2013) 43:60-72. doi: 10.1111/cea.12040

28. Alcantara-Neves NM, Veiga RV, Ponte JC, da Cunha SS, Simões SM, Cruz ÁA, et al. Dissociation between skin test reactivity and anti-aeroallergen IgE: determinants among urban Brazilian children. PLoS ONE. (2017) 12:e0174089. doi: 10.1371/journal.pone. 0174089

29. Amoah AS, Obeng BB, Larbi IA, Versteeg SA, Aryeetey Y, Akkerdaas JH, et al. Peanut-specific IgE antibodies in asymptomatic Ghanaian children possibly caused by carbohydrate determinant cross-reactivity. J Allergy Clin Immunol. (2013) 132:639-47. doi: 10.1016/j.jaci.2013.04.023

30. Amoah AS, Boakye DA, Yazdanbakhsh M, van Ree R. Influence of parasitic worm infections on allergy diagnosis in Sub-Saharan Africa. Curr Allergy Asthma Rep. (2017) 17:65. doi: 10.1007/s11882-017-0733-y

31. Sousa-Santos ACAF, Moreno AS, Santos ABR, Barbosa MCR, Aragon DC, Sales VSF, et al. Parasite infections, allergy and asthma: a role for tropomyosin in promoting type 2 immune responses. Int Arch Allergy Immunol. (2020) 181:221-7. doi: 10.1159/000504982

32. Acevedo N, Sánchez J, Erler A, Mercado D, Briza P, Kennedy M, et al. IgE cross-reactivity between Ascaris and domestic mite allergens: the role of tropomyosin and the nematode polyprotein ABA-1. Allergy. (2009) 64:163543. doi: 10.1111/j.1398-9995.2009.02084.x

33. Santiago HDC, Nutman TB. Role in allergic diseases of immunological crossreactivity between allergens and homologues of parasite proteins. Crit Rev Immunol. (2016) 36:1-11. doi: 10.1615/CritRevImmunol.2016016545

34. Arkestal K, Sibanda E, Thors C, Troye-Blomberg M, Mduluza T, Valenta $\mathrm{R}$, et al. Impaired allergy diagnostics among parasite infected patients caused by IgE antibodies to the carbohydrate epitope galactose-alpha 1,3galactose. J Allergy Clin Immunol. (2011) 127:1024-8. doi: 10.1016/j.jaci.2011. 01.033

35. Souza da Cunha S, Barreto ML, Fiaccone RL, Cooper PJ, AlcantaraNeves NM, Simões Sde M, et al. Asthma cases in childhood attributed to atopy in tropical area in Brazil. Rev Panam Salud Publica. (2010) 28:40511. doi: 10.1590/S1020-49892010001200001

36. Montealegre F, Meyer B, Chardon D, Vargas W, Zavala D, Hart B, et al. Comparative prevalence of sensitization to common animal, plant and mould allergens in subjects with asthma, or atopic dermatitis and/or allergic rhinitis living in a tropical environment. Clin Exp Allergy. (2004) 34:518. doi: $10.1111 / j .1365-2222.2004 .01855 . x$

37. Sanchez-Borges M, Capriles-Hulett A, Caballero-Fonseca F, FernandezCaldas E. Mite and cockroach sensitization in allergic patients from Caracas, Venezuela. Ann Allergy Asthma Immunol. (2003) 90:664-8. doi: 10.1016/S1081-1206(10)61873-X

38. Andiappan AK, Puan KJ, Lee B, Nardin A, Poidinger M, Connolly J, et al. Allergic airway diseases in a tropical urban environment are driven by dominant mono-specific sensitization against house dust mites. Allergy. (2014) 6:501-9. doi: 10.1111/all.12364

39. Aranda CS, Cocco RR, Pierotti FF, Sarinho E, Sano F, Porto A, et al. Allergic sensitization pattern of patients in Brazil. J Pediatr. (2021) 4:38795. doi: 10.1016/j.jped.2020.08.005

40. Catanghal RA, Paller VG. Mite fauna and mite antigen detection in house dust found in residential areas in Los Banos, Laguna, Philippines. Southeast Asian J Trop Med Public Health. (2012) 43:1114-21.

41. Valdivieso $R$, Iraola $V$, Estupiñán $M$, Fernández-Caldas E. Sensitization and exposure to house dust and storage mites in highaltitude areas of Ecuador. Ann Allergy Asthma Immunol. (2006) 97:532-8. doi: 10.1016/S1081-1206(10)60946-5

42. Fernández-Caldas E, Puerta L, Mercado D, Lockey RF, Caraballo LR. Mite fauna, Der p I, Der f I and Blomia tropicalis allergen levels in a tropical environment. Clin Exp Allergy. (1993) 23:292-7. doi: 10.1111/j.1365-2222.1993.tb00325.x
43. Puerta L, Fernández-Caldas E, Lockey RF, Caraballo LR. Mite allergy in the tropics: sensitization to six domestic mite species in Cartagena, Colombia. $J$ Investig Allergol Clin Immunol. (1993) 3:198-204.

44. Amberbir A, Medhin G, Erku W, Alem A, Simms R, Robinson K, et al. Effects of Helicobacter pylori, geohelminth infection and selected commensal bacteria on the risk of allergic disease and sensitization in 3-year-old Ethiopian children. Clin Exp Allergy. (2011) 41:142230. doi: $10.1111 / \mathrm{j} .1365-2222.2011 .03831 . x$

45. Djuardi Y, Supali T, Wibowo H, Kruize YC, Versteeg SA, van Ree R, et al. The development of $\mathrm{TH} 2$ responses from infancy to 4 years of age and atopic sensitization in areas endemic for helminth infections. Allergy Asthma Clin Immunol. (2013) 9:13. doi: 10.1186/1710-1492-9-13

46. Boye JI. Food allergies in developing and emerging economies: need for comprehensive data on prevalence rates. Clin Transl Allergy. (2012) 2:25. doi: $10.1186 / 2045-7022-2-25$

47. Sanchez J, Sanchez A. Epidemiology of food allergy in Latin America. Allergol Immunopathol. (2015) 43:185-95. doi: 10.1016/j.aller.2013.07.001

48. Ochoa-Avilés C, Morillo D, Rodriguez A, Cooper PJ, Andrade S, Molina $\mathrm{M}$, et al. Prevalence and risk factors for asthma, rhinitis, eczema, and atopy among preschool children in an Andean city. PLoS ONE. (2020) 15:e0234633. doi: 10.1371/journal.pone. 0234633

49. Morillo-Argudo DA, Andrade Tenesaca DS, Rodas-Espinoza CR, Perkin MR, Gebreegziabher TL, Zuñiga GA, et al. Food allergy, airborne allergies, and allergic sensitisation among adolescents living in two disparate socioeconomic regions in Ecuador: a cross-sectional study. World Allergy Organ J. (2020) 13:100478. doi: 10.1016/j.waojou.2020.100478

50. Valdivieso R, Abril L, Iraola V, Estupiñan M, Correa E, Del Carmen Romero M. Skin sensitization and classroom exposure to dermatophagoides pteronyssinus and dermatophagoides farinae allergens in andean ecuadorian students. J Trop Pediatr. (2011) 57:319-20. doi: 10.1093/tropej/fmp105

51. Celedon JC, Sredl D, Weiss ST, Pisarski M, Wakefield D, Cloutier M. Ethnicity and skin test reactivity to aeroallergens among asthmatic children in Connecticut. Chest. (2004) 125:85-92. doi: 10.1378/chest.125.1.85

52. Vince N, Limou S, Daya M, Morii W, Rafaels N, Geffard E, et al. Association of HLA-DRB109:01 with tIgE levels among Africanancestry individuals with asthma. J Allergy Clin Immunol. (2020) 146:147-55. doi: 10.1016/j.jaci.2020.01.011

53. Moncayo AL, Lovato R, Cooper PJ. Soil-transmitted helminth infections and nutritional status in Ecuador: findings from a national survey and implications for control strategies. BMJ Open. (2018) 8:e021319. doi: 10.1136/bmjopen-2017-021319

54. Ege MJ. The hygiene hypothesis in the age of the microbiome. Ann Am Thorac Soc. (2017) 14:S348-53. doi: 10.1513/AnnalsATS.201702-139AW

55. Campbell B, Raherison C, Lodge CJ, Lowe AJ, Gislason T, Heinrich J, et al. The effects of growing up on a farm on adult lung function and allergic phenotypes: an international population-based study. Thorax. (2017) 72:23644. doi: 10.1136/thoraxjnl-2015-208154

56. Deckers J, Lambrecht BN, Hammad H. How a farming environment protects from atopy. Curr Opin Immunol. (2019) 60:163-9. doi: 10.1016/j.coi.2019.08.001

57. Guadalupe I, Mitre E, Benitez S, Chico ME, Cordova X, Rodriguez $\mathrm{J}$, et al. Evidence of intrauterine sensitization to Ascaris lumbricoides infection in newborns of infected mothers. J Infect Dis. (2009) 199:184650. doi: $10.1086 / 599214$

58. Steel C, Guinea A, McCarthy JS, Ottesen EA. Long-term effect of prenatal exposure to maternal microfilaraemia on immune responsiveness to filarial parasite antigens. Lancet. (1984) 343:890-3. doi: 10.1016/S0140-6736(94)90009-4

59. Endara P, Vaca M, Chico ME, Erazo S, Oviedo G, Quinzo I, et al. Long-term periodic anthelmintic treatments are associated with increased allergen skin reactivity. Clin Exp Allergy. (2010) 40:1669-77. doi: 10.1111/j.1365-2222.2010.03559.x

60. Ballardini N, Kull I, Lind T, Hallner E, Almqvist C, Ostblom E, et al. Development and comorbidity of eczema, asthma and rhinitis to age 12: data from the BAMSE birth cohort. Allergy. (2012) 67:53744. doi: 10.1111/j.1398-9995.2012.02786.x

61. de Jong NW, Elbert NJ, Mensink-Bout SM, van der Valk JPM, Pasmans SGMA, Jaddoe VWV, et al. Parental and child factors 
associated with inhalant and food allergy in a population-based prospective cohort study: the Generation R Study. Eur J Pediatr. (2019) 178:1507-17. doi: 10.1007/s00431-019-03441-5

62. Kuehr J, Karmaus W, Forster J, Frischer T, Hendel-Kramer A, Moseler M, et al. Sensitization to four common inhalant allergens within 302 nuclear families. Clin Exp Allergy. (1993) 23:600-5. doi: 10.1111/j.1365-2222.1993.tb00900.x

63. Wan YI, Strachan DP, Evans DM, Henderson J, McKeever T, Holloway JW, et al. A genome-wide association study to identify genetic determinants of atopy in subjects from the United Kingdom. $J$ Allergy Clin Immunol. (2011) 127:223-31. doi: 10.1016/j.jaci.2010. 10.006

64. Szepfalusi Z, Pichler J, Elsasser S, van DK, Ebner C, Bernaschek G, et al. Transplacental priming of the human immune system with environmental allergens can occur early in gestation. J Allergy Clin Immunol. (2000) 106:5306. doi: 10.1067/mai.2000.108710

65. Acevedo N, Alashkar Alhamwe B, Caraballo L, Ding M, Ferrante A, Garn $\mathrm{H}$, et al. Perinatal and early-life nutrition, epigenetics, and allergy. Nutrients. (2021) 13:724. doi: 10.3390/nu13030724
Conflict of Interest: The authors declare that the research was conducted in the absence of any commercial or financial relationships that could be construed as a potential conflict of interest.

Publisher's Note: All claims expressed in this article are solely those of the authors and do not necessarily represent those of their affiliated organizations, or those of the publisher, the editors and the reviewers. Any product that may be evaluated in this article, or claim that may be made by its manufacturer, is not guaranteed or endorsed by the publisher.

Copyright (c) 2021 Cooper, Chis Ster, Chico, Vaca, Barreto and Strachan. This is an open-access article distributed under the terms of the Creative Commons Attribution License (CC BY). The use, distribution or reproduction in other forums is permitted, provided the original author(s) and the copyright owner(s) are credited and that the original publication in this journal is cited, in accordance with accepted academic practice. No use, distribution or reproduction is permitted which does not comply with these terms. 